\title{
Implicações Econômicas da Reforma Tributária: Análise com um Modelo CGE*
}

\author{
Octávio Augusto Fontes Tourinho ${ }^{\dagger}$, Yann Le Boulluec Alves ${ }^{\ddagger}$, \\ Napoleão Luiz Costa da Silva ${ }^{\S}$
}

Conteúdo: 1. Introdução; 2. A Reforma Tributária de 2003; 3. A Metodologia; 4. Simulações da Reforma Tributária; 5. Conclusão;

Palavras-chave: Tributação; Tributos Indiretos; Reforma Tributária; Equilíbrio Geral Computável.

Códigos JEL: $\quad$ H25; H22; D58.

Este artigo utiliza um modelo de equilíbrio geral computável (CGE) da economia brasileira para medir os impactos de alterações recentes na estrutura tributária nacional. Ele descreve o modelo, discute suas características, formulação, construção e calibração, e o usa para analisar três medidas fiscais: a transformação parcial da COFINS em uma contribuição sobre o valor adicionado e a incidência dos PIS/PASEP e da COFINS sobre as importações, ambas aprovadas em 2003, e a extinção da CPMF, que só foi adotada em 2007. A análise de estática comparativa permite identificar detalhadamente os efeitos destas medidas sobre o desempenho econômico agregado e setorial no longo prazo, depois que todos os seus efeitos transitórios se esgotem e que os seus efeitos indiretos sejam absorvidos.

This paper uses a computable general equilibrium model (CGE) on the Brazilian economy to measure the impacts of recent changes in the national tax structure. It describes the model, discusses its characteristics, formulation, construction and calibration, and uses it to analyze three tax changes: the partial transformation of COFINS into a contribution over value added, and the incidence of PIS/PASEP and COFINS on imports, both approved in 2003, and the extinction of CPMF, which was adopted only in 2007. The comparative static analysis allows the detailed identification of the long term

\footnotetext{
* Parte deste estudo foi realizado no âmbito do convenio de cooperação técnica entre o BNDES e o IPEA, até 2007. A metodologia, implementação, interpretação, conclusões e opiniões contidas neste documento são dos autores, e não representam necessariamente aquelas das instituições às quais eles estão vinculados. Agradecemos os comentários e sugestões de um avaliador anônimo desta revista sobre uma versão anterior deste artigo.

†Universidade do Estado do Rio de Janeiro - UERJ. E-mail: octavio.tourinho@terra.com.br

‡Programa Nacional de Pesquisa Economica - PNPE. E-mail: yannlba@hotmail .com

$\S$ Diretoria de Macroeconomia do Instituto de Pesquisa Econômica Aplicada - IPEA. E-mail: napoleao.silva@ipea.gov.br
} 
effects of those changes on economic performance, at the macro and sector levels, after all the transitory effects are exhausted, and their indirect effects are absorbed.

\section{INTRODUÇÃO}

Este artigo mostra como um modelo de equilíbrio geral computável (CGE) pode ser utilizado para avaliar o impacto econômico de alterações na política tributária. Ele descreve o modelo, discute suas características, formulação, construção, calibração, e uso, para analisar as duas medidas principais da reforma tributária de 2003, e a rejeição, em 2007, da proposta de emenda constitucional que prorrogaria o prazo de vigência da CPMF até 2011.

As medidas aprovadas em 2003 procuram reduzir a cumulatividade de impostos e contribuições, que é um dos principais problemas no sistema tributário brasileiro. ${ }^{1}$ Uma delas, aprovada através da Emenda Constitucional 42 de 19/12/2003 e de alteração na legislação ordinária, transformou parte da COFINS em tributo incidente sobre o valor adicionado, substituindo a incidência sobre o faturamento. Ela eliminou, em parte, a ocorrência de impostos em cascata, mas teve um alcance bastante limitado porque mudou a base de arrecadação em apenas alguns setores, e atingiu somente cerca de $40 \%$ do montante daquelas contribuições. Outra medida também tomada na ocasião instituiu a incidência do PIS-COFINS sobre as importações, corrigindo um viés que as favorecia frente à produção nacional, e atingiu seus objetivos. Outro passo importante para reduzir a cumulatividade no sistema tributário brasileiro foi dado em 2007 com a extinção da CPMF, que incidia sobre todas as operações de movimentação financeira, inclusive o faturamento.

Estas medidas, no entanto, são apenas uma pequena parte das modificações do sistema tributário nacional que vem sendo estudadas nos últimos anos. Várias outras medidas contidas na proposta de reforma tributária enviada ao Congresso Nacional em 2003 não foram adotadas e estão em discussão até hoje, através de nova proposta enviada em fevereiro de 2008. A metodologia aqui empregada para analisar os impactos das medidas já aprovadas poderá ser utilizada para avaliar o impacto deste novo conjunto de propostas, assim que a sua configuração mais provável fique clara.

Há alguns estudos na literatura brasileira que avaliam os efeitos sobre a economia das medidas contidas nas principais propostas de reforma tributária. Eles adotam, na sua maioria, a abordagem de equilíbrio parcial e medem apenas o impacto direto daquelas medidas como fazem, por exemplo, Varsano et alii (2001). No entanto, alguns estudos procuram medir também alguns dos seus efeitos indiretos, apesar de também utilizarem a abordagem de equilíbrio parcial. Eles são discutidos sinteticamente a seguir.

Siqueira et alii (2001) calculam a incidência econômica dos impostos indiretos sobre o preço dos bens para as várias categorias da demanda final utilizando a matriz insumo-produto de 1996, e supondo que os produtores conseguem repassar todo o ônus do imposto para os compradores dos bens. ${ }^{2}$ A implicação desta hipótese depende do componente de demanda considerado: na demanda final ele

\footnotetext{
${ }^{1}$ Antes do início da reforma tributária, os principais tributos cumulativos eram o PIS (Programa de Integração Social), COFINS (Contribuição para o Financiamento da Seguridade Social) e a CPMF (Contribuição Provisória sobre Movimentação Financeira). Eles foram responsáveis por mais de 36,7\% da receita administrada pela Secretaria da Receita Federal (SRF) no ano de 2002. Além destes, há outros impostos como o IRPJ e a CSLL (quando cobrados sobre o lucro presumido), e o SIMPLES que são cobrados como um percentual fixo do faturamento e são, portanto, cumulativos. O ISS também é um imposto cumulativo, e a incidência do IPI sobre bens de capital gera tributação em cascata adicional. Varsano et alii (2001) mostram que a substituição dos impostos em cascata por outros já estava em pauta por ocasião das discussões da reforma tributária no Congresso Nacional no início da década.

${ }^{2}$ Eles calculam o impacto setorial do ICMS, IPI, ISS, II e dos Outros Impostos Indiretos, mas não levam em consideração o PISPASEP e a COFINS. Os autores não esclarecem porque não incluíram as contribuições na análise, apesar da metodologia utilizada também poder, aparentemente, ser aplicada para calcular o impacto de modificações na arrecadação delas.
} 
é repassado imediatamente para o consumidor, enquanto na demanda intermediária ele é repassado para o setor produtivo que adquire o insumo. Neste último caso, ele é em seguida transferido para os compradores dos bens produzidos pelo setor, processo que se repete sucessivamente até que o total de impostos indiretos recaia sobre os consumidores finais.

Kume (2004) estima os efeitos sobre a estrutura de incentivos à produção doméstica da transformação do PIS-COFINS em contribuições sobre o valor adicionado. Ele calcula a incidência setorial daquelas contribuições utilizando uma metodologia semelhante à empregada por Siqueira et alii (2001), mas supõe que são os setores produtores de bens comercializáveis que arcam com a totalidade do imposto, enquanto nos setores de bens não-comercializáveis os impostos são totalmente repassados para os compradores. Assim, a carga total de impostos indiretos em um setor produtor de um bem comercializável resulta igual à soma do imposto incidente sobre o seu faturamento com os tributos que lhe são repassados na aquisição de insumos não-comercializáveis, tanto de forma direta quanto indireta. ${ }^{3}$

Os estudos de equilíbrio parcial fazem hipóteses simplificadoras quanto ao impacto das medidas tributárias, principalmente nas quantidades produzidas, que são mantidas constantes, ou respondem a elas de acordo com regras comportamentais pré-estabelecidas. Estas são, por exemplo, a manutenção do faturamento e o valor adicionado líquidos de impostos de cada setor produtivo no mesmo nível observado antes da alteração tributária. Este tipo de abordagem limita a precisão da estimativa do impacto das medidas, e o rol de efeitos que se pode explorar com modelos deste tipo. Os modelos de equilíbrio geral, que utilizamos aqui, apesar de serem mais complexos, não têm esta limitação porque levam em conta os efeitos das medidas sobre cada agente da economia, e sobre o equilíbrio econômico agregado.

De modo diverso dos modelos de equilíbrio parcial, os modelos de equilíbrio geral aplicados não fazem hipóteses ex-ante quanto ao repasse dos impostos entre agentes econômicos, deixando que o grau em que ele ocorre seja determinado no próprio modelo, pelos preços e quantidades no equilíbrio após a alteração tributária. Portanto, a incidência dos tributos é endógena, e não é predeterminada, pois depende simultaneamente dos parâmetros que caracterizam a estrutura de mercado, a oferta, a demanda doméstica, e o grau de concorrência externa dos vários setores. A transferência total dos impostos indiretos para os consumidores pode resultar do próprio equilíbrio econômico do modelo, sem que isto seja uma hipótese de incidência. ${ }^{4}$

O uso de modelos CGE para simular os efeitos econômicos e distributivos de política fiscal e tributária está consagrado na literatura internacional. O marco inicial é Shoven e Whalley $(1972,1973)$ que propuseram a metodologia, a que se seguiram algumas aplicações importantes que ajudaram a difundí-la, como, por exemplo, Whalley (1977). Adelman e Robinson (1978) foram pioneiros na introdução de aspectos distributivos nos modelos CGE voltados para questões tributárias, e esta preocupação permeia boa parte desta literatura desde então. Ela se justifica porque a equidade é uma dimensão importante do sistema tributário, e o cálculo do impacto distributivo permite avaliar do efeito das medidas sobre ela. Dervis et alii (1982) propõem a utilização de modelos CGE para análise de tributação e de outras políticas públicas em países em vias de desenvolvimento, e propõe um modelo genérico que

\footnotetext{
${ }^{3}$ Há dois problemas principais com esta abordagem. O primeiro é que ela tem subjacente a hipótese de que a taxa de câmbio é fixa. Se ela variar em resposta à mudança tributária, o preço internado das importações varia, afetando o preço que pode ser cobrado pelo produtor de bens comercializáveis, o que permite algum grau de repasse de tributos no caso de desvalorização. 0 segundo problema diz respeito à classificação dicotômica dos setores que ela exige, entre comercializáveis ou não. Na realidade, principalmente considerando a classificação setorial agregada da matriz insumo produto, há gradações no grau de exposição ao comércio internacional dos vários setores, e é improvável que elas possam ser capturadas de modo satisfatório com estas situações polares.

${ }^{4}$ No modelo há mercados competitivos, tecnologia de produção com retornos constantes de escala, ausência de produtos conjuntos, e apenas um insumo não-produzido, satisfazendo algumas das hipóteses para repasse integral. Entretanto, outras hipóteses também necessárias para que ele ocorra não são satisfeitas, porque nos nossos mercados de fatores de produção há limitações de oferta e não há uma dicotomia entre bens transacionáveis e não, uma vez que há uma gradação continua no que se refere a esta característica, pois cada bem é a agregação de bens de origem doméstica e importada, que são substitutos imperfeitos.
} 
foi largamente utilizado posteriormente. Ballard et alii (1985) desenvolveram um modelo para análise de questões de tributação para os EUA que foi adotado como protótipo em vários outros estudos posteriores desta natureza (modelo BFSW). Shoven e Whalley (1992) aprofundam a discussão de como os modelos CGE podem ser utilizados na prática para desenhar políticas públicas de vários tipos, inclusive tributárias. Os modelos CGE são atualmente utilizados de modo rotineiro para análise de questões de política tributária, tanto em países desenvolvidos e em vias de desenvolvimento, como também em economias sub-nacionais. Exemplos disto são Berck et alii (1996) para o estado da Califórnia (EUA), Fehr (2000) para a Alemanha, Baylor e Beauséjour (2004) para o Canadá, e Ahmed (2007) para o Paquistão.

A lista de contribuições apresentada acima não pretende ser exaustiva, pois tem como objetivo apenas destacar algumas das mais importantes, e demonstrar que a análise de política tributária com modelos CGE é uma metodologia que vem sendo desenvolvida há décadas, e que ainda se encontra em uso corrente. Além disto, o volume de trabalho que vem sendo produzido no exterior com o uso desta abordagem sugere que ela é um elemento importante para avaliação destas políticas, e que suas conclusões são prestigiadas. Portanto, um esforço de aplicar este tipo de modelo para avaliação de medidas tributárias no Brasil, como fazemos neste artigo, se justifica e legitima frente à experiência relatada na literatura internacional, e na prática usual de desenho da política tributária de outros países.

Na literatura econômica brasileira há alguns estudos que utilizam modelos de equilíbrio geral com objetivo similar ao deste artigo, como comentamos a seguir. Os dois primeiros têm seu foco em um prazo mais longo, e fazem uma abordagem mais teórica e menos detalhada, do ponto de vista de representação da estrutura econômica da economia, do que a abordagem aqui apresentada. $O$ terceiro e quarto usam modelos CGE similares ao nosso, mas obtém resultados distintos.

Araújo e Ferreira (1999) usam um modelo de equilíbrio geral dinâmico com agentes que têm vida infinita e taxa de desconto intertemporal positiva, e discutem as medidas da reforma tributária tal como estavam propostas no final da última década. Eles comparam a eficiência do sistema resultante da implantação delas e recomendam a adoção das mais eficientes, dentro daquela ótica de longo prazo. Já Lledo $(2001,2005)$ utiliza um modelo de equilíbrio geral dinâmico de gerações superpostas do tipo daquele proposto por Auerbach e Kotlikoff (1987) para analisar a implementação das propostas de reforma tributária, e também para discutir os aspectos delas que dizem respeito à distribuição de renda entre gerações.

Fochezatto (2003) utiliza um modelo na linha daqueles discutidos em Mercenier e Srinivasan (1994) para avaliar as implicações de medidas de reforma tributária, mas o faz em um contexto mais geral do que o apresentado aqui. Cury e Coelho (2006) fazem uma avaliação da transformação da base de incidência do PIS-COFINS de faturamento para valor adicionado em um modelo cuja formulação deriva de Dervis et alii (1982), Derajavan et alii (1991), e Robinson et alii (1999), tal como o modelo aqui apresentado. A principal diferença entre aquele artigo e o nosso é quanto ao seu foco, que no nosso caso é mais setorial, voltado para os impactos nos preços e quantidades de equilíbrio, enquanto no deles é mais agregado, voltado para o impacto no produto e no bem estar agregado. Esta diferença induz diferenças importantes na formulação do modelo, como por exemplo, a utilização de uma representação do mercado de trabalho baseada na existência de uma curva ad-hoc com inclinação negativa que relaciona, a nível setorial, salários à taxa de desemprego. Há outras diferenças, também, quanto à representação do sistema tributário, e no modo como é feita a desagregação da mão de obra e das famílias, sobre as quais não vamos nos estender aqui. Estas diferenças na formulação se refletem na mensuração dos impactos da reforma tributária nas quantidades produzidas dos bens que são, no nosso modelo, mais modestos. Em contrapartida, no nosso modelo os impactos nos preços são, de modo geral, mais significativos do que no deles, devido à ausência de fontes de rigidez nominal.

O restante do artigo é organizado da seguinte forma: na próxima seção descrevemos os principais aspectos da reforma tributária que estamos avaliando, a metodologia empregada é apresentada na Seção 3, a Seção 4 discute as simulações das medidas da reforma tributária, e a última seção apresenta as principais conclusões. 


\section{A REFORMA TRIBUTÁRIA DE 2003}

As medidas de natureza tributária são modificações na base e na alíquota de impostos e contribuições que alteram a distribuição da carga tributária entre os setores produtivos, mesmo que a carga total permaneça constante. Um dos objetivos deste artigo é antecipar estas alterações tendo como base a distribuição anterior e a caracterização das medidas.

Para colocá-las em perspectiva é conveniente descrever de modo sintético a estrutura tributária antes de reforma de 2003, em 2001, quando a arrecadação dos impostos indiretos foi $64,2 \%$ da carga tributária ampla naquele ano, de $33,8 \%$ do PIB. ${ }^{5}$ A participação dos vários impostos na arrecadação dos impostos indiretos foi como se segue: o ICMS correspondeu a 33,6\%, o IPI mais o ISS a 8,8\%, as contribuições para a Previdência e para o FGTS a 25,3\%, e os outros impostos sobre a produção (que correspondem basicamente a PIS-COFINS) a $28,1 \%$. Os setores mais atingidos pelos impostos indiretos, usando como indicador a razão entre a arrecadação total e o valor bruto da produção, foram os de comunicações $(38,2 \%)$, indústria de transformação $(37,7 \%)$, transportes $(37,4 \%)$ e comércio $(34,1 \%)$. Podem-se identificar também os setores mais atingidos por cada um dos impostos específicos, usando aquele mesmo indicador: para o ICMS foram as comunicações $(27,2 \%)$ e serviços industriais de utilidade pública (17\%), para a previdência e FGTS foram os transportes $(11,6 \%)$ e comércio $(10,1 \%)$, e para os outros impostos indiretos (que consistem principalmente do PIS-COFINS), foi a indústria de transformação.

As medidas da reforma tributária de 2003 são o objeto das duas primeiras simulações apresentadas adiante. Elas reduziram significativamente a distorção na alocação de recursos e a perda de competitividade dos produtos nacionais frente aos importados causados pelo sistema tributário. $O$ viés na alocação de recursos se deve à incidência dos impostos em cascata que, mesmo com alíquota uniforme, geram uma carga tributária efetiva distinta sobre cada bem final que distorce os preços relativos e, portanto, as decisões de produção e consumo. ${ }^{6}$ Além disto, os tributos cumulativos induzem a integração vertical ineficiente da produção que reduz o grau de competição da economia, porque o número de vezes que a contribuição em cascata é cobrada diminui quando se reduz o número de transações intermediárias. A perda de competitividade ocorria porque a produção doméstica estava sujeita à tributação cumulativa de COFINS e CPMF ao longo de toda cadeia produtiva, enquanto aqueles tributos só incidiam sobre os produtos importados na etapa de comercialização ou, no caso dos insumos, depois de se incorporarem à produção de cada setor.?

Outras medidas que foram aprovadas no âmbito da reforma tributária de 2003 não foram simuladas neste artigo porque, apesar de serem relevantes do ponto de vista do seu impacto fiscal, não se referiam à estrutura do sistema tributário propriamente dita, ou porque tinham caráter específico ou conjuntu$\mathrm{ral}^{8}$ Outras duas medidas não foram simuladas porque não tiveram impacto imediato, uma vez que apenas criaram a possibilidade de mudanças (futuras) na tributação. ${ }^{9}$

Dentre as medidas que não foram aprovadas em 2003, mas o foram posteriormente, está a extinção da CPMF (Contribuição Provisória sobre a Movimentação Financeira). Ela incidia sobre qualquer opera-

\footnotetext{
${ }^{5}$ Obtém-se a carga tributária indireta excluindo da carga total os impostos sobre a renda, propriedade e movimentação financeira.

${ }^{6} \mathrm{O}$ impacto depende, entre outras coisas, do número de transações realizadas ao longo da cadeia produtiva e da participação de bens intermediários importados na produção do bem final.

${ }^{7}$ Uma interpretação alternativa, sugerida por um parecerista anônimo, não suporta o argumento de isonomia apresentado no texto. Ela supõe que os formuladores da legislação que instituiu aquelas contribuições teriam isentado as importações visando compensar em parte a perda de competitividade delas com relação a produção nacional devida à incidência da tarifa de importação ad-valorem sobre elas. Neste caso, a medida da reforma tributária de 2003 implicaria em um aumento do preço relativo dos importados, e perda de bem-estar.

${ }^{8}$ Entre estas medidas se insere a elevação do prazo de vigência da Zona Franca de Manaus em 10 anos, e a manutenção, em 20\% da arrecadação, da desvinculação das receitas da União, e a prorrogação da vigência da CPMF até 2007, com uma alíquota de $0,38 \%$.

${ }^{9}$ Estas medidas são a adoção de um novo regime simplificado de tributação unificado, envolvendo os três níveis de governo, e o financiamento dos Fundos Estaduais com adicional de 2\% nas alíquotas do ICMS de bens supérfluos.
} 
ção que representasse circulação de moeda, independentemente de que dela resultasse transferência da titularidade dos valores, créditos e direitos. Com uma alíquota ad-valorem de 0,38\%, ela permitiu uma arrecadação de cerca de R $\$ 40$ bilhões em 2007. A sua destinação específica era a saúde pública, mas ela foi utilizada também para o financiar programas sociais. Por ser um imposto sobre faturamento, a CPMF tinha os defeitos discutidos acima com referência ao COFINS, mas apresentava algumas qualidades, enquanto instrumento fiscal, devido à sua ampla base de incidência, à sua alíquota reduzida que não estimulava a evasão, e ao seu eficiente sistema de arrecadação. A terceira simulação que apresentamos adiante se refere os impactos da sua eliminação.

Neste estudo avaliamos os efeitos destas medidas sobre a configuração de longo prazo da economia brasileira (preços, produções setoriais, etc.), depois que todos os seus efeitos transitórios tenham se esgotado, e depois da absorção pela economia de todos os seus efeitos indiretos. A metodologia empregada é a de estática comparativa, que confronta uma situação inicial (o cenário básico), com outras derivadas da introdução das medidas tributárias no modelo (os experimentos). Nesta abordagem associam-se àquelas medidas as mudanças observadas nos preços e quantidades de equilíbrio obtidas da solução do modelo, quando se compara o cenário básico aos experimentos.

\section{A METODOLOGIA}

O modelo de equilíbrio geral aplicado (CGE) empregado neste estudo é uma especialização de um modelo mais geral anteriormente desenvolvido para o Brasil. Ele é derivado de um modelo CGE da economia brasileira que foi construído por Sherman Robinson (IFPRI) em 1996, no âmbito de um contrato de consultoria para o BNDES. A sua formulação original é similar à encontrada em Derajavan et alii (1991), mas ele atualmente já incorpora um número elevado de modificações feitas desde então visando aprimorar a sua formulação e ajustá-lo à estrutura da economia brasileira.

Usamos aqui a segunda versão da adaptação daquele modelo para a análise detalhada de questões de natureza tributária. Ela é um aprimoramento substancial da versão anterior, descrita em Silva et alii (2005), em dois aspectos principais. O primeiro é a atualização do ano-base do modelo para 2003, medida que permite um avanço significativo na representatividade do modelo com relação à versão anterior, cujo ano de referência era 1998, porque ocorreram mudanças estruturais importantes nos 5 anos de intervalo entre aquelas duas datas. O segundo é a introdução dos elementos necessários para avaliar os impactos distributivos das medidas tributárias, dimensão que não era contemplada anteriormente. A nova base de dados do modelo, consolidada na matriz de contabilidade social (SAM) para 2003, cuja construção é descrita em Silva et alii (2006), levou em conta estas modificações. ${ }^{10}$

A escolha de 2003 para novo ano-base ocorreu porque ele era o último ano para o qual os dados estavam disponíveis na época do início desta pesquisa. Entretanto, como já se passaram quatro anos desde então, poder-se-ia colocar em duvida a adequação do uso do modelo atualmente. Acreditamos que não há motivos para esta preocupação por duas razões principais:

(a) a análise é apresentada e discutida na forma de variações relativas, o que reduz a dependência das conclusões quanto aos níveis das variáveis no ano-base;

(b) a análise heurística da evolução recente da economia nacional sugere que os parâmetros estruturais, dos quais a resposta do modelo depende mais intensamente, permaneceram aproximadamente constantes entre 2003 e 2008.

\footnotetext{
${ }^{10}$ A construção da SAM 2003 exigiu mais do que a simples atualização da anterior, pois contemplou a desagregação da mão de obra por grau de especialização e por tipo de relação de emprego, e das famílias por classe de renda, além de incorporar uma série de outros aprimoramentos. Além disto, estas desagregações foram feitas simultaneamente, para assegurar a consistência interna da sub-matriz correspondente da SAM, que explicita como a renda da família representativa, nas diferentes classes de renda, se origina nos mercados de trabalho dos quais seus membros participam.
} 
Esta nova versão do modelo mantém a mesma desagregação setorial daquele que lhe serviu de base, contemplando 39 setores que se identificam com os setores da matriz insumo produto do Brasil (com poucas exceções), e que produzem, cada um, apenas um bem ou serviço.

Para tratar do aspecto distributivo, adaptamos o modelo e construímos a sua base de dados de modo a desagregar o fator trabalho e a família representativa. A formulação do modelo passou a admitir a existência de seis tipos de fator trabalho, estratificados de acordo com o grau de especialização do chefe da família e da natureza do mercado de mão de obra (formal ou informal), e de onze famílias representativas, discriminadas segundo as classes de renda da POF - Pesquisa de Orçamentos Familiares. ${ }^{11}$ Os ajustes do modelo aproveitaram algumas estratégias de modelagem propostas por Lofgren et alii (2002).

Para uma interpretação mais detalhada da natureza dos impactos calculados pelo modelo é necessário levar em conta suas características gerais. Para discutí-las apresentamos na próxima seção as principais equações do modelo, e as suas implicações.

\subsection{Descrição do modelo CGE}

O modelo aqui utilizado é baseado em Robinson et alii (1999), que propõe um modelo CGE padrão voltado para a análise de políticas públicas. Como outros modelos de equilíbrio geral aplicado, ele calcula os preços e quantidades transacionadas dos bens e fatores de produção sob a hipótese de comportamento racional dos agentes econômicos, de equilíbrio simultâneo de todos os mercados da economia, e de atendimento das duas principais restrições macroeconômicas: a identidade entre poupança e investimento agregados, e a condição de equilíbrio do balanço de pagamentos.

As contribuições da produção doméstica e do setor externo no atendimento da demanda interna e externa estão representados de modo esquemático na Figura 1, que mostra como os blocos de equações descritos abaixo de inter-relacionam.

\section{PRODUÇÃO}

O produto de cada setor $j$ é denotado $X_{j}$, e a sua tecnologia é representada por uma função de produção setorial que emprega capital, que tem composição distinta em cada setor, e vários tipos de trabalho, que refletem o grau de especialização do trabalhador e a natureza do mercado onde ele atua. Supõe-se que a função de produção é do tipo CES, como indicado na equação (1),

$$
X_{j}=\Omega_{j}\left[\sum_{f} \alpha_{j f} \cdot F_{j f}^{-\rho_{j}}\right]^{\frac{-1}{\rho_{j}}}
$$

onde, em cada setor $j$, a elasticidade de substituição global (entre todos os fatores) é igual a $\sigma_{j}=$ $\left(1+\rho_{j}\right)^{-1}, F_{j f}$ é a quantidade empregada de cada fator $f, \alpha_{j f}$ representa o seu peso relativo da produção setorial, e $\Omega_{j}$ mede a produtividade total dos fatores, também denominado parâmetro de escala. Por convenção, o índice do fator capital é igual à unidade $(f=1)$.

Pode-se representar a gama de situações encontradas nos diferentes setores produtivos da economia real quanto à facilidade de substituição entre os fatores apenas variando o expoente da equação (1) e, portanto, a elasticidade de substituição. Se $\sigma_{j}=0$ obtém-se a função de produção de Leontief, de proporções fixas entre fatores, e se $\sigma_{j} \rightarrow \infty$ produz-se uma fronteira de produção linear com substituição perfeita entre fatores. Nos casos intermediários a combinação de fatores depende dos seus preços relativos. Quando $\sigma_{j}=1$ temos o caso especial da função de produção Cobb-Douglas, onde a razão entre os dispêndios com os fatores é constante.

\footnotetext{
${ }^{11}$ A extensão da formulação do modelo exigiu principalmente o detalhamento da incidência dos impostos sobre o fator trabalho e sobre os diferentes tipos de mão-de-obra, e sobre as famílias das diferentes classes de renda.
} 
Figura 1: Estrutura da produção e setor externo no modelo CGE

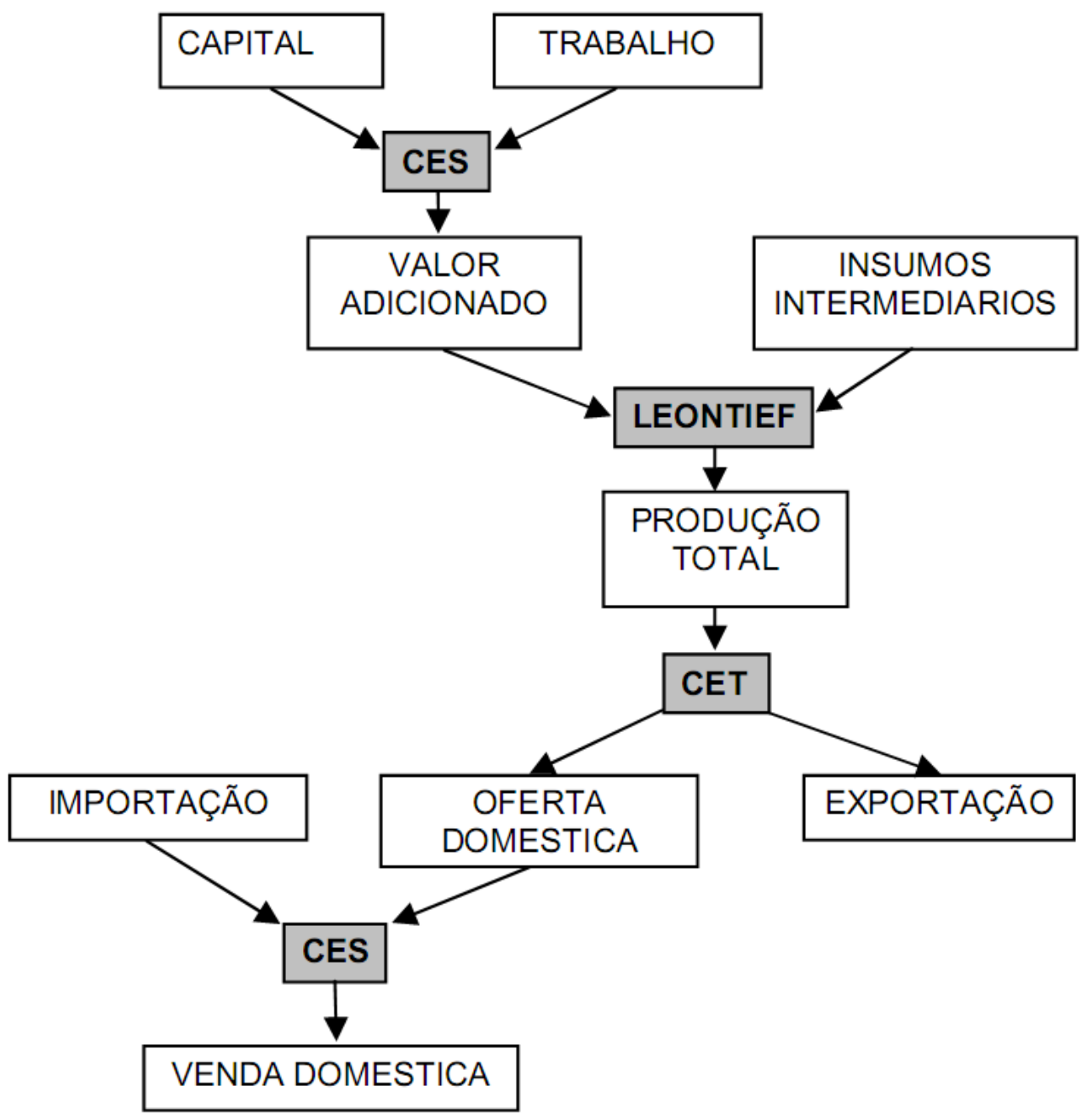


Supõe-se que as firmas representativas dos setores produtivos da economia agem de modo competitivo, maximizando o seu lucro, tomando os preços como dados. As condições marginais que determinam a escolha de insumos são representadas pela equação (2), ${ }^{12}$

$$
W_{i f} \sum_{g} \alpha_{j g} F_{j g}^{-\rho_{j}}=X_{j} P_{j}^{V} \alpha_{j f} F_{j f}^{-\rho_{j}-1}
$$

onde $W_{i f}$ é a remuneração unitária do fator $f$ no setor $j$, e $P_{j}^{V}$ é o "preço" do valor adicionado do setor $j$ e as outras variáveis são como definidas acima. Este último preço é definido pela condição de que o valor adicionado setorial seja igual a $X_{j} P_{j}^{V} \cdot{ }^{13}$

A equação (3) garante que haja equilíbrio entre a oferta total de cada fator $\left(\bar{F}_{f}\right)$ e a sua demanda total pelos setores.

$$
\bar{F}_{f}=\sum_{j} F_{j f}
$$

Para os vários tipos de fator trabalho $(f>1)$, isto significa que a oferta total seja exaurida pela demanda setorial, e que não há transição de trabalhadores entre as diversas categorias aqui consideradas. Portanto, os trabalhadores podem mudar de setor, mas não podem se deslocar entre o mercado formal e informal, nem aumentar o seu nível de qualificação.

Para o capital $(f=1)$ isto significa que há maleabilidade do capital, ou seja, ele pode ser desinstalado do setor onde se encontra e reinstalado em outro setor, como detalhado adiante, na seção que discute o investimento.

\section{DEMANDA}

Por simplicidade, o modelo supõe que cada setor produz um único bem composto, e isto induz uma relação biunívoca entre setores e bens. Portanto, a estrutura setorial da economia pode ser representada por uma matriz insumo-produto quadrada cujo elemento representativo $a_{i j}$ é a quantidade do bem $i$ demandada por unidade de produção do setor $j$. A demanda de insumos intermediários é dada pela multiplicação entre aquela matriz e o vetor de produção setorial bruta $X .{ }^{14}$ O equilíbrio macroeconômico é especificado pela equação (4) onde a oferta de cada bem composto $\left(Q_{i}\right)$ deve atender a demanda intermediária mais a demanda para consumo final das famílias $\left(C_{i h}\right)$, consumo do governo $\left(G_{i}\right)$, e investimento $\left(I_{i}\right)$.

$$
Q_{i}=\sum_{j} a_{i j} X_{j}+\sum_{h} C_{i h}+G_{i}+I_{i}
$$

No sistema insumo-produto a quantidade de cada bem ofertada domesticamente por cada setor (denominada $S_{i}$ ) é relacionada às vendas domésticas das atividades (denominada $D_{j}$ ) pela matriz make, cujos elementos $z_{i j}$ indicam a proporção da produção total do bem $j$ que é ofertada pelo setor $i$, como indicado na equação (5).

$$
S_{i}=\sum_{j} z_{i j} D_{j}
$$

\footnotetext{
${ }^{12}$ Para a derivação desta condição, veja adiante a seção sobre calibração do modelo.

${ }^{13}$ Uma outra equação para o preço do valor adicionado pode ser derivada a partir da condição de que o lucro setorial deve ser nulo no equilíbrio, que implica que o valor adicionado mais o custo dos insumos deve ser igual ao faturamento setorial. Esta será uma das últimas equações a ser apresentada, porque envolve variáveis fiscais que serão introduzidas mais adiante.

${ }^{14}$ Os índices $i$ (bens), e $j$ (setores) podem então ser usados de modo indistinto nas equações que se seguem.
} 
No nosso modelo a matriz make é empregada para levar em conta a existência, nas contas nacionais, de margens de distribuição de tal modo que cada setor produz uma cesta de bens e serviços: o produto (propriamente dito), mais os dois serviços correspondentes à sua comercialização e transporte (distribuição). Como há uma correspondência biunívoca entre os setores e os produtos, os elementos da matriz make que não estão nas linhas correspondentes aqueles dois bens constituem uma matriz identidade.

A equação dual correspondente a (5) é (6), que permite calcular o preço dos bens ofertados domesticamente $\left(P_{i}^{D}\right)$ a partir do custo das atividades $\left(P_{j}^{S}\right)$, somando as margens de comercialização e transporte ao custo direto de produção.

$$
P_{j}^{D}=\sum_{i} z_{i j} P_{i}^{S}
$$

\section{RENDA}

Admitimos que há mobilidade dos fatores entre setores, mas reconhecemos que os fatores de produção não são perfeitamente homogêneos, e adquirem algumas características particulares do setor em que são aplicados. Para o fator trabalho isto se deve a competências setoriais específicas desenvolvidas pelos trabalhadores de cada tipo. Para o capital, esta diferenciação reflete as variações da sua composição, que discutiremos mais adiante, e da rentabilidade da produção setorial, devida a diferenças na relação capital-produto e na depreciação. Para levar estes aspectos em conta, não se impõe a equalização de remuneração dos fatores entre os setores, e admite-se que a estrutura de diferenciação setorial do salário das diversas categorias ${ }^{15}$ e da remuneração do capita ${ }^{16}$ continue sendo igual àquela observada no ano-base, como indicado em (7),

$$
W_{j f}=\tilde{W}_{f} \cdot \psi_{j f}
$$

onde os elementos $\psi_{j f}$ da matriz de distribuição setorial da renda dos fatores são a razão entre a renda do fator $f$ no setor $j$ e a renda média daquele fator na economia $\widetilde{W}_{f}$. A renda total de cada fator, representada por $Y_{f}^{F}$, é a soma das suas rendas setoriais, calculadas como o produto entre a remuneração e a quantidade demandada respectiva, como indicado em (8).

$$
Y_{f}^{F}=\sum_{j} W_{i f} F_{j f}
$$

A renda doméstica líquida de cada fator a distribuir entre as famílias, denominada renda institucional $\left(Y_{f}^{I}\right)$, é indicada em (9). Ela é a renda total do fator calculada acima, deduzida da contribuição para a seguridade social $\left(S S T A X_{f}\right)$, quando se tratar da renda do trabalho formal, e da renda do fator enviada ao exterior $\left(L A B T F_{f}\right)$. Como esta última é indicada em divisas, ela é convertida em moeda doméstica multiplicando pela taxa de câmbio, expressa em unidades da moeda doméstica necessárias para adquirir uma unidade de divisas $(E X R)$.

$$
Y_{f}^{I}=Y_{f}^{F}-E X R \cdot L A B T F_{f}-S S T A X_{f \in \text { formal }} \quad f>1
$$

Para calcular a renda doméstica líquida do capital, como indicado na equação (10), deduz-se do lucro os seguintes itens: a renda enviada ao exterior pelas empresas $(E N T T F)$, convertida para moeda doméstica pela multiplicação pela taxa de câmbio, a parcela do lucro retida para futuro aumento de

\footnotetext{
${ }^{15}$ Esta dispersão da remuneração dos diferentes tipos a mão de obra, por setor, pode ser claramente observada nos dados da PNAD, por exemplo, a aparece na SAM 2003.

${ }^{16}$ Uma alternativa a esta hipótese de mobilidade do capital (putty-puty), seria admitir que o capital é maleável apenas antes de ser instalado, ficando rígido a partir de então (putty-clay).
} 
capital ( $E N T S A V)$, o dispêndio com reposição da depreciação $(D E P R E C)$, e o imposto de renda das pessoas jurídicas $(E N T T A X)$. Estes três últimos itens são calculados nas equações (34), (32) e Tabela 1, respectivamente.

$$
Y_{1}^{I}=Y_{1}^{F}-(E X R . E N T T F+E N T S A V+E N T T A X+D E P R E C)
$$

A renda enviada para o exterior pelas empresas $(E N T T F)$ é denominada em divisas, e é igual à soma das remunerações do capital estrangeiro de empréstimo e de risco. A primeira parcela corresponde ao pagamento dos juros da sua dívida externa, igual ao produto entre o seu estoque $\left(D^{E X}\right)$ e a taxa de juros externa $(T J X)$. A segunda parcela, também expressa em divisas, é igual à parcela não retida para futuro aumento de capital do retorno do estoque de capital estrangeiro de risco $(K X)$, líquida de depreciação e imposto sobre a renda, como indicado na equação (11),

$$
E N T T F=D^{E X} . T J X+\left(1-s^{E}\right)\left(1-t^{K}\right)(T J R-\bar{\delta}) \frac{K X}{E X R}
$$

onde $T J R$ é a taxa de juros externa, $s^{E}$ é a taxa de poupança das empresas, $t^{K}$ é a alíquota do imposto de renda das empresas, e a taxa média de depreciação $\bar{\delta}$ é calculada do modo indicado em (12),

$$
\bar{\delta}=\sum_{j} \delta_{j} F_{j 1} / \sum_{j} F_{j 1}
$$

onde $\delta_{j}$ é a taxa de depreciação setorial.

O cálculo da renda familiar total está indicado na equação (13). Ela é igual à soma das parcelas da renda doméstica líquida de cada fator, acrescida das parcelas apropriadas pela família $h$ dos juros da dívida interna $(J D I N T)$, das transferências de seguridade social $(S S T R)$ e das remessas recebidas do exterior pelas famílias (REMIT).

$$
Y_{h}^{H}=\sum_{f} \omega_{h f} Y_{f}^{I}+v_{h}^{R} \cdot E X R \cdot R E M I T+v_{h}^{J} . J D I N T+v_{h}^{S} . S S T R
$$

O cálculo da apropriação destes valores pelas classes de renda familiar se faz através de matrizes de distribuição entre as famílias representativas das diferentes classes de renda da renda dos fatores $\left(\omega_{h f}\right)$, e dos juros $\left(v_{h}^{J}\right)$, das transferências da seguridade social $\left(v_{h}^{S}\right)$, e das remessas do exterior $\left(v_{h}^{R}\right)$. Estas matrizes são exógenas, e podem sofrer mudanças paramétricas nos exercícios de estática comparativa feitos com o modelo. ${ }^{17} \mathrm{Na}$ medida em que famílias nas diferentes classes de renda capturam proporções distintas da renda dos diferentes fatores, a alteração da remuneração relativa dos fatores tem o potencial de alterar a distribuição da renda entre as famílias.

\section{CONSUMO}

O consumo familiar é representado por um sistema de dispêndios lineares (LES), onde o dispêndio com cada bem $\left(C_{i h}\right)$ é uma fração fixa da renda disponível, como indicado em (14)

$$
P_{i}^{C} C_{i h}=\left(1-s_{h}\right) \beta_{i h}^{H}\left[\left(1-t_{h}^{H}\right) Y_{h}^{H}-I N F T A X\right]
$$

onde, para cada classe de renda $h, s_{h}$ é a taxa marginal de poupança, $\beta_{i h}^{H}$ é a fração do dispêndio familiar destinada à aquisição do bem $i, t_{h}^{H}$ é a alíquota do imposto sobre a renda das pessoas físicas, $Y_{H}^{h}$ é definido acima, $P_{i}^{C}$ é o preço do bem $i$ ao nível do consumidor definido pela equação (15), onde $t_{i}^{C}$ é a alíquota do imposto sobre consumo.

\footnotetext{
${ }^{17}$ As famílias são segregadas em grupos segundo a classe de renda, mas a composição destes grupos é mantida fixa, e não se altera com a variação da renda média do grupo. Não há migração de famílias de uma classe para outra.
} 


$$
P_{i}^{C}=\left(1-t_{i}^{C}\right) P_{i}^{Q}
$$

o gasto público total $G^{T}$ é exógeno, e se distribui pelos bens nas proporções $\beta_{i}^{G}$, como indicado em (16).

$$
G_{i}=G^{T} \cdot \beta_{i}^{G}
$$

\section{SETOR EXTERNO}

No comércio exterior há substituição suave entre importações e produção doméstica no atendimento à demanda interna (hipótese de Armington), e também na alocação da produção entre o mercado doméstico e exportações. Supõe-se que o fluxo de poupança externa é exógeno e, portanto, a restrição de equilíbrio no balanço de pagamentos determina a taxa de câmbio. ${ }^{18}$

A demanda de cada bem composto $\left(Q_{i}\right)$ é atendida por uma combinação de bens ofertados domesticamente $\left(D_{i}\right)$ e importações $\left(M_{i}\right)$, e a substituição entre eles é caracterizada por uma função CES (elasticidade constante de substituição) com parâmetros de distribuição, escala, e substituição iguais a $\gamma_{i}^{C}, \kappa_{i}^{C}$ e $\varphi_{i}^{C}$, respectivamente, como indicado em (17). Este último parâmetro é diretamente relacionado à elasticidade de substituição, pela expressão $\varphi_{j}^{C}=1 / \sigma_{j}^{C}-1$.

$$
Q_{i}=\kappa_{i}^{C}\left[\gamma_{i}^{C} D_{i}^{-\varphi_{i}^{C}}+\left(1-\gamma_{i}^{C}\right) M_{i}^{-\varphi_{i}^{C}}\right]^{1 / \varphi_{i}^{C}}
$$

A combinação ótima de produção doméstica e de importações é função de seus preços relativos, como indicado em (18),

$$
\frac{M_{i}}{D_{i}}=\left[\frac{P_{i}^{D}}{P_{i}^{M}} \frac{\gamma_{j}^{C}}{\left(1-\gamma_{j}^{C}\right)}\right]^{\frac{1}{1+\varphi_{i}^{C}}}
$$

onde $P_{i}^{D}$ é o preço doméstico (definido na equação (6)), e $P_{i}^{M}$ é o preço internacional internado dado pela equação (19), que calcula o preço para a firma importadora,

$$
P_{i}^{M}=P_{i}^{W M} \cdot \operatorname{EXR} \cdot\left(1+t_{i}^{M}+t_{i}^{A D M}\right)
$$

onde $t_{i}^{M}=$ alíquota do imposto de importação, $t_{i}^{A D M}=$ alíquota dos impostos adicionais sobre importações (ICMS, IPI, etc.), e $P_{i}^{W M}=$ o preço mundial (em divisas) das importações.

Como o valor do bem agregado tem que ser igual à soma dos custos dos seus componentes, o preço de venda satisfaz à equação (20)

$$
P_{i}^{Q}=\left(P_{i}^{D} D_{i}+P_{i}^{M} M_{i}\right) / Q_{i}
$$

A produção de cada setor pode ser direcionada para atender o mercado doméstico $\left(D_{j}\right)$ ou para exportação $\left(E_{j}\right)$, e supõe-se que esta distribuição se faz de modo que a o bem produzido domesticamente $\left(X_{j}\right)$ seja uma agregação CET (elasticidade constante de transformação) destes dois tipos de bens, diferenciados por destino, com parâmetros de escala, distribuição e transformação respectivamente iguais a $\kappa_{j}^{X}, \gamma_{j}^{X}$ e $\varphi_{j}^{X}$, como indicado em (21). Este último parâmetro é diretamente relacionado à elasticidade de transformação, pela expressão $\gamma_{j}^{T}=1 / \sigma_{j}^{T}+1$.

$$
X_{j}=\kappa_{j}^{T}\left[\left(1-\gamma_{j}^{T}\right) S_{j}^{\varphi_{j}^{T}}+\gamma_{j}^{T} E_{j}^{\varphi_{j}^{T}}\right]^{1 / \varphi_{j}^{T}}
$$

\footnotetext{
${ }^{18}$ Para uma formulação onde a poupança externa é endógena, veja Maldonado et alii (2007).
} 
A destinação ótima da produção entre o bem para consumo doméstico e aquele destinado às exportações depende dos preços relativos deles, como indicado em (22),

$$
\frac{E_{j}}{S_{j}}=\left[\frac{P_{j}^{E}}{P_{j}^{S}} \frac{1-\gamma_{j}^{T}}{\gamma_{j}^{T}}\right]^{\frac{1}{\varphi_{j}^{T}-1}}
$$

onde $P_{j}^{S}$ é o preço doméstico do bem composto produzido pela atividade $j$, e $P_{j}^{E}$ é o preço internacional internado do bem exportado, definido em (23), onde $P_{j}^{W E}$ é o preço internacional das exportações (em divisas), e $t_{j}^{E}$ é a alíquota dos subsídios às exportações.

$$
P_{j}^{E}=P_{j}^{W E} \cdot E X R \cdot\left(1+t_{j}^{E}\right)
$$

Lembrando que o valor do bem agregado tem que ser igual à soma dos custos dos seus componentes, resulta que o preço do bem composto produzido domesticamente $\left(P_{j}^{X}\right)$ é dado pela equação (23), onde a remuneração do exportador por unidade exportada é $P_{j}^{E}$ em moeda doméstica, dado por (24).

$$
P_{i}^{X}=\left(P_{i}^{S} D_{i}+P_{i}^{E} M_{i}\right) / X_{i}
$$

\section{INVESTIMENTO}

Como indicado na equação (25), o valor do investimento bruto no setor $j$ (de destino) é igual ao produto entre o preço do investimento no setor $\left(P_{j}^{K}\right)$ e o acréscimo bruto de capacidade setorial $\left(\Delta K_{j}\right)$. Exceto para o setor de administração pública $(j=g)$, ele deve ser igual à soma do investimento líquido no setor com o investimento de reposição da depreciação.

$$
P_{j}^{K} \Delta K_{j}=\pi_{j}(I N V E S T-G O V I N V-D E P R E C)+P_{j}^{K} \delta_{j} F_{j 1} \quad j \neq g
$$

Supondo que a alocação setorial do investimento privado líquido é exógena, mas suscetível de análises de sensibilidade, admite-se que ele é uma fração $\pi_{j}$ do seu valor total, que é igual ao investimento bruto (INVEST) deduzido do valor da depreciação $(D E P R E C)$ e do investimento público $(G O V I N V) .{ }^{19}$

O valor da depreciação setorial é o produto entre o preço do capital no setor e uma fração $\left(\delta_{j}\right)$ do capital setorial $\left(F_{j 1}\right)$, como indicado no último termo do lado direito da equação (25). 0 dispêndio total em reposição da depreciação é a soma destes valores para todos os setores, como indicado na equação (26).

$$
D E P R E C=\sum_{j} \delta_{j} P_{j}^{K} F_{j 1}
$$

Como indicado na equação (27), o investimento público é determinado pelo equilíbrio do fluxo de caixa do governo. Ele é igual à soma da poupança pública $(G O V S A V)$, o imposto inflacionário (INFT AX), o aumento do endividamento interno $\left(\Delta D^{G I}\right)$ e externo $\left(\Delta D^{G X}\right)$, e as perdas de reservas $(L S F R E S)$. Como estes dois últimos valores são denominados em divisas, eles são multiplicados pela taxa de câmbio.

$$
G O V I N V=G O V S A V+I N F T A X+\Delta D^{G I}+\left(L S F R E S+\Delta D^{G X}\right) \cdot E X R
$$

\footnotetext{
${ }^{19}$ É possível alterar a hipótese adotada no modelo quanto à alocação do investimento para, por exemplo, admitir que uma parcela da remuneração do capital de cada setor é retida e utilizada para investimento no próprio setor, sendo a parcela remanescente distribuída entre os outros setores, privilegiando aqueles que apresentam maior demanda por investimentos e maior rentabilidade do capital relativamente à média da economia, como indicado na subseção 5.6 de Dervis et alii (1982).
} 
onde $G O V S A V$ é calculada na equação (34), INFTAX encontra-se nas equações do bloco fiscal do modelo (abaixo), e a perda de reservas é exógena nesta versão do modelo com taxa de câmbio flutuante. o investimento do governo GOVINV converte-se em aumento líquido do estoque de capital público, pois não se considera que ele se deprecie (equação (28)).

$$
P_{g}^{K} \Delta K_{g}=\text { GOVINV } \quad g=\text { governo }
$$

A transformação do vetor de investimento por setor de destino em um vetor de demanda de bens de investimento é feita multiplicando-o por uma matriz que traduz a composição setorial do capital, cujos elementos $b_{i j}$ são a quantidade do bem $i$ empregada por unidade de aumento de capacidade no setor $j$, como indicado na equação (29). ${ }^{20}$

$$
I_{i}=\sum_{j} b_{i j} \Delta K_{j} \quad i \neq \text { governo }
$$

Como os setores que produzem os bens de capital são competitivos, o preço deles será dado pelo seu custo, como indicado na equação (30) .

$$
P_{j}^{K}=\sum_{i} P_{i}^{C} b_{i j}
$$

\section{POUPANÇA}

A poupança agregada $(S A V I N G)$ é dada por (31), onde $H H S A V$ é a poupança das famílias, $G O V S A V$ é a poupança do governo, que é a diferença entre arrecadação tributária e o dispêndio do Governo, $D E P R E C$ é a depreciação total, igual à soma das depreciações setoriais, e $F S A V$ (em divisas) é a poupança externa, todas definidas a seguir.

$$
S A V I N G=H H S A V+G O V S A V+E N T S A V+D E P R E C+F S A V . E X R
$$

Como indicado em (32), a poupança líquida das famílias ( $H H S A V)$ é a poupança bruta, igual a uma fração constante da renda correspondente $\left(s_{h}^{H}\right)$, como indicado anteriormente, deduzida do imposto sobre a renda das famílias, cuja alíquota é $t_{h}^{H}$.

$$
H H S A V=\sum_{h} s_{h}^{H}\left[\left(1-t_{h}^{H}\right) Y_{h}^{H}-I N F T A X\right]
$$

A poupança das empresas é representada por $E N T S A V$, e corresponde à parcela $s^{E}$ dos lucros setoriais, líquidos do imposto sobre a renda das pessoas jurídicas e da depreciação, que é retida para investimentos, como indicado em (33).

$$
E N T S A V=s^{E}\left(\sum_{j} W_{j 1} F_{j 1}-E N T T A X-D E P R E C\right)
$$

Como indicado na equação (34), a poupança do governo $(G O V S A V)$, é igual ao seu resultado em conta corrente, obtido subtraindo da receita de impostos $(G R)$, calculada em (38), os seguintes itens: o valor total das compras do governo, dos juros da dívida interna $(J D I N T)$, das transferências para

\footnotetext{
${ }^{20} \mathrm{O}$ cálculo das taxas de depreciação setorial é feito na fase de calibração do modelo e leva em conta a composição setorial do capital, como representado pela equação $\delta_{j}=\sum_{i} \theta_{i} b_{i j}$, onde $\theta_{i}$ é a taxa de depreciação do bem de capital $i$, o que assegura a consistência do modelo.
} 
a seguridade social $(S S T R)$ e das transferências para o exterior $(G O V T F)$ contabilizadas em moeda doméstica.

$$
G O V S A V=G R-\sum_{i} P_{i}^{C} G_{i}-J D I N T-S S T R-G O V T F . E X R
$$

Os juros da dívida interna são calculados na equação (35), onde $D^{G I}$ é o montante da dívida interna do governo, e $T R J$ é a taxa de juros paga pelo governo no seu endividamento. ${ }^{21}$ Admite-se que em equilíbrio ela seja igual à taxa média de retorno sobre o capital, com indicado em equação (36).

$$
\begin{gathered}
J D I N T=\left(D^{G I}+\frac{\Delta D^{G I}}{2}\right) T J R \\
T J R=\sum_{j} W_{j 1} F_{j 1} / \sum_{j} F_{j 1}
\end{gathered}
$$

A transferência do governo ao exterior, expressa em divisas, se refere ao pagamento de juros sobre a dívida pública externa $\left(D^{G X}\right)$, e é calculada em (37), onde $T J X$ é a taxa de juros externa.

$$
G O V T F=D^{G X} . T J X
$$

\section{BLOCO TRIBUTÁRIO}

A Tabela 1 sintetiza as variáveis e definições do bloco tributário do modelo antes das medidas fiscais aqui consideradas. Ela é similar à maneira como os impostos e tributos aparecem nas tabelas de usos e recursos das contas nacionais, mas há uma diferença importante. Como nas contas nacionais até 2003 os impostos sobre valor adicionado (IPI e ICMS) estão agregados ao imposto sobre consumo $(C O N T A X)$, mas isto não reflete corretamente a sua base de cálculo, explicitamos a arrecadação do ICMS e IPI como uma nova variável denominada $V A T$, cuja arrecadação é proporcional ao valor adicionado, e representamos a parcela remanescente dos impostos sobre o consumo com a nova variável $C O N T A X^{\prime}$, que continua incidindo sobre o consumo.

Para simular as medidas da reforma tributária alteramos algumas alíquotas e bases de cálculo da Tabela 1, indicados com aspas na Tabela 2, e introduzimos duas novas variáveis, $A D T A X M$ e $C V A$, que representam, respectivamente, os impostos indiretos (basicamente ICMS e IPI) cobrados sobre importações, e a nova contribuição social, que passou a incidir sobre o valor adicionado. A arrecadação dos impostos indiretos, deduzida da $C V A$, é representada por uma nova variável $\left(I N D T A X^{\prime}\right)$.

A receita do governo depois da reforma tributária é agregação da receita dos impostos que aparecem nas Tabelas 1 e 2, e é indicado na equação (38).

$$
\begin{array}{r}
G R=T A R I F F+C O N T A X^{\prime}+I N D T A X^{\prime}+H H T A X+E N T T A X \\
E X P T A X+I N F T A X+S S T A X+V A T+C V A+A D T A X M
\end{array}
$$

A base de dados do modelo também foi ajustada à nova formulação do bloco tributário, desagregando a matriz de contabilidade social (SAM). Foram criadas linhas correspondentes aos novos tributos, e a arrecadação foi redistribuída com base na estrutura da matriz de relações intersetoriais e também a partir de informações fiscais coletadas junto à Secretaria de Receita Federal para este fim. As alíquotas correspondentes às novas receitas tributárias ( $V A T, C V A$ e $A D T A X M)$, bem como os novos valores para aquelas já existentes no modelo anteriormente (INDTAX e CONTAX) foram calculadas

${ }^{21} \mathrm{O}$ cálculo dos juros pagos pelo governo na equação (33) implicitamente assume que o aumento de endividamento ocorre de modo linear ao longo do período. 
Tabela 1: Impostos, taxas e contribuições no modelo CGE antes da reforma

\begin{tabular}{|c|c|c|c|c|}
\hline Variável & Item & Alíquota & Nome base & Valor base \\
\hline$I N D T A X$ & Imposto indireto sobre produção $^{1}$ & $t_{j}^{X}$ & Valor da produção doméstica & $P_{j}^{S} S_{j}$ \\
\hline CONTAX & Imposto sobre consumo ${ }^{2}$ & $t_{i}^{C}$ & Valor da oferta de bens & $P_{i}^{Q} Q_{i}$ \\
\hline$H H T A X$ & Imposto de renda das famílias ${ }^{3}$ & $t_{h}^{H}$ & Renda das famílias & $Y_{h}^{H}$ \\
\hline ENTTAX & Imposto de renda das empresas ${ }^{4}$ & $t^{K}$ & Remuneração líquida do capital & $\begin{array}{c}\sum_{j} W_{j 1} F_{j 1}- \\
D E P R E C\end{array}$ \\
\hline$S S T A X$ & Contribuição para a seguridade social & $t_{j}^{S S}$ & Valor da massa salarial & $\sum_{f>1} W_{j f} F_{j f}$ \\
\hline$E X P T A X$ & Taxa (+) ou subsídio (-) na exportação & $t_{i}^{E}$ & Valor das exportações & $E X R \cdot P_{i}^{W E} E_{i}$ \\
\hline$T A R I F F$ & Tarifa de importação & $t_{i}^{M}$ & Valor das importações & $E X R \cdot P_{i}^{W M} M_{i}$ \\
\hline INFTAX & Imposto Inflacionário & $\epsilon$ & Base monetária & $M 0$ \\
\hline
\end{tabular}

Tabela 2: Impostos, taxas e contribuições, acrescentados ou modificados no modelo CGE

\begin{tabular}{|c|c|c|c|c|}
\hline Variável & Item & Alíquota & Nome base & Cálculo da base \\
\hline$I N D T A X^{\prime}$ & Imposto indireto sobre produção ${ }^{1}$ & $t_{j}^{X^{\prime}}$ & Valor da produção doméstica & $\sum_{i} P_{i}^{S} D_{i}$ \\
\hline$C O N T A X^{\prime}$ & Imposto sobre consumo ${ }^{2}$ & $t_{i}^{C^{\prime}}$ & Valor da oferta de bens & $P_{i}^{Q} Q_{i}$ \\
\hline$V A T$ & Imposto sobre valor adicionado ${ }^{3}$ & $t^{V A T}$ & Total do valor adicionado & $\sum_{i} P_{i}^{V} X_{i}$ \\
\hline$C V A$ & Contrib. social sobre valor adicionado ${ }^{4}$ & $t^{C V A}$ & Total do valor adicionado & $\sum_{i} P_{i}^{V} X_{i}$ \\
\hline$A D T A X M$ & Imposto adicional sobre as importações ${ }^{5}$ & $t_{j}^{A D M}$ & Valor das importações & $E X R . P_{i}^{W M^{M}} M_{i}$ \\
\hline \multicolumn{5}{|c|}{${ }^{1} \mathrm{O}$ imposto indireto sobre a produção no modelo modificado corresponde ao do modelo original deduzido do PIS/PASEP. } \\
\hline \multicolumn{5}{|c|}{${ }^{2}$ O imposto sobre consumo no modelo modificado corresponde ao do modelo original deduzido dos valores relativos a ICMS e IPI. } \\
\hline \multicolumn{5}{|c|}{${ }^{3}$ Este valor corresponde basicamente à ICMS e IPI. } \\
\hline \multicolumn{5}{|c|}{$\begin{array}{l}{ }^{4} \text { Na simulação do caso base (antes da reforma tributária), este valor corresponde ao PIS/PASEP, e no cenário com reforma ele corresponde à } \\
\text { arrecadação do PIS/PASEP e da COFINS sobre o valor adicionado. }\end{array}$} \\
\hline \multicolumn{5}{|c|}{$\begin{array}{l}{ }^{5} \text { Este tributo inclui ICMS e IPI sobre importações no cenário básico, e na simulação da reforma tributária além destes inclui a taxação adicional } \\
\text { sobre importações devido à incidência do PIS/COFINS sobre elas. }\end{array}$} \\
\hline
\end{tabular}

de modo a reproduzir os valores correspondentes no ano- base, obtidos da SAM. As modificações dos valores destas alíquotas devidas à reforma tributária são indicadas adiante, na seção que descreve as simulações.

\section{EQUILÍBRIO MACROECONÔMICO}

Na tradição dos modelos de dois hiatos, há duas condições macroeconômicas que devem ser simultaneamente satisfeitas no equilíbrio: a igualdade entre poupança e investimento e neutralidade do balanço de pagamentos, que são discutidas a seguir.

O equilíbrio entre renda e produto é garantido pela equação (39).

$$
I N V E S T=S A V I N G
$$


O fluxo de poupança externa $(F S A V)$ contribui tanto para o equilíbrio agregado quanto para o equilíbrio do balanço de pagamentos. O cálculo de $F S A V$ é indicado em (40), onde $R E M I T_{h}$ são as remessas do exterior para residentes, $L A B T F_{f}, E N T T F$ e GOVTF representam respectivamente a transferência de renda para o exterior feitas pelos vários tipos de fator trabalho, empresas e governo.

$$
\begin{aligned}
F S A V & =\sum_{i}\left(P_{i}^{W M} M_{i}-P_{i}^{W E} E_{i}\right)+\sum_{f} L A B T F_{f} \\
& +E N T T F+G O V T F-\sum_{h} R E M I T_{h}
\end{aligned}
$$

A poupança externa também aparece na equação (41), de equilíbrio do balanço de pagamentos, onde $L S F R E S$ é a perda de reservas, FORINV é o investimento estrangeiro direto, $\Delta D^{G X}$ e $\Delta D^{E X}$ são o aumento do endividamento externo público e privado, como indicado anteriormente.

$$
F S A V=L S F R E S+F O R I N V+\Delta D^{G X}+\Delta D^{E X}
$$

\section{VALOR ADICIONADO E PRODUTO AGREGADO}

Podemos agora definir em (42) o preço do valor adicionado setorial $\left(P_{i}^{V}\right)$ de tal modo que o valor adicionado setorial $\left(X_{i} P_{i}^{V}\right)$ seja igual ao valor da produção líquida de impostos indiretos e insumos.

$$
P_{i}^{V}=\left[P_{i}^{X}-\sum_{j} a_{i j} P_{j}^{C}-t_{i}^{X} \frac{P_{i}^{S} S_{i}}{X_{i}}\right] /\left(1+t^{V A T}+t^{C V A}\right)
$$

A equação 43 define a renda nacional e o produto real é definido por (44).

$$
\begin{aligned}
G D P V A & =\sum_{i} P_{i}^{V} \cdot X_{i}+I N D T A X+C O N T A X+V A T \\
& +A D T A X M+C V A+T A R I F F+E X P T A X \\
R G D P & =\sum_{i}\left[C_{i}^{D}+I_{i}+G_{i}+E_{i}-\left(1-t_{i}^{M} M_{i}\right)\right]
\end{aligned}
$$

\subsection{Calibração do modelo}

A calibração do modelo consiste em especificar, ou calcular, valores para todos os seus parâmetros e variáveis exógenas de tal modo que a sua solução no cenário de referência reproduza o ano-base. Vamos discutir como isto é feito de modo genérico, para cada tipo de variável, pois a descrição mais detalhada é inviável no espaço aqui disponível.

As variáveis exógenas, para as quais não há equação comportamental no modelo, são fixadas no nível observado na SAM, mas podem ser modificadas nas simulações para calcular os cenários de experimento. 22

Convenciona-se que todos os preços dos bens, aos vários níveis (produtor, consumidor, etc.) no anobase são iguais à unidade. Isto é possível porque se admite que a unidade na qual cada um dos fluxos físicos é medido é a quantidade que se poderia adquirir no ano-base com uma unidade monetária. Deste

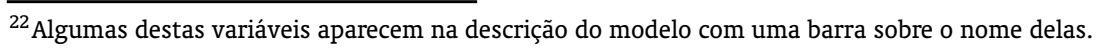


modo pode-se calcular os valores iniciais para quantidades de todas as variáveis que representam as decisões dos agentes a partir de uma SAM que é composta de células que contém valores que representam fluxos monetários. Portanto, sob esta hipótese, a matriz de fluxos de bens tem a mesma representação numérica daquela das células da sub-matriz correspondente da SAM.

O índice de preços, por ser uma média ponderada de preços cujo valor é unitário, é também unitário. Nos experimentos é imposta uma restrição de que o índice de preços permaneça igual à unidade, de modo que as variações dos preços individuais são variações de preço relativo. O modelo CGE não tem elementos para determinar variações absolutas de preços ou, dito de modo mais geral, o vetor de preços calculado em equilíbrio geral é homogêneo de grau 1.

As alíquotas dos impostos são calculadas como a razão entre a sua arrecadação no ano-base e a base sobre a qual eles incidem, indicada nas Tabelas 2 e 3. Portanto, as alíquotas no modelo são as efetivas, e modificações paramétricas nos seus valores nominais tem que ser convertidas em variações nas tarifas efetivas para que possam ser simuladas. A remuneração unitária dos fatores de produção é calculada dividindo-se o valor total da remuneração do fator pela quantidade dele, que é informada à parte porque ela não consta de SAM.

Para caracterizar a tecnologia de produção, de agregação das importações e produção doméstica, e de desagregação das vendas entre demanda doméstica e exportações, o modelo se serve de funções CES, como se viu nas equações (1), (17) e (21), respectivamente. Os parâmetros daquelas funções são calculados de tal modo que os fluxos observados na SAM para o ano-base sejam viáveis e ótimos, admitindo que as elasticidades de substituição sejam conhecidas. Os valores aqui utilizados para elas são apresentados na Tabela 3, e são provenientes de Tourinho et alii (2007), no caso das elasticidades de Armington, e de uma compilação de valores para outros países, no caso das elasticidades de substituição na produção e das elasticidades de transformação.

Para todas as funções CES o processo de calibração é similar. Para as equações (17) e (21) ele é mais simples, porque ela envolve substituição entre dois agregados apenas, e há apenas uma condição marginal (equações (18) e (22)). Para a equação (1) a calibração é mais complexa, porque envolve vários fatores e, portanto, várias condições marginais. Ambos são descritos a seguir.

o procedimento adotado nos casos mais simples pode ser exemplificado pela calibração da equação (17), pois um procedimento inteiramente análogo a este é utilizado para calibrar os parâmetros da equação (21).

Inicialmente calcula-se o parâmetro de distribuição $\gamma_{i}^{C}$ resolvendo a equação (18), tomando como dado o vetor de quantidades e preços que caracteriza o equilíbrio parcial $\left(M_{i}, D_{i}, P_{i}^{M}\right.$ e $\left.P_{i}^{D}\right)$, como indicado na equação (45). O parâmetro de escala $\kappa_{i}^{C}$ pode então ser calculado invertendo a equação (17).

$$
\gamma_{i}^{C}=\frac{1}{1+\theta_{i}^{C}}, \text { onde } \theta_{i}^{C}=\frac{\gamma_{i}^{C}}{1-\gamma_{i}^{C}}=\frac{P_{i}^{M}}{P_{i}^{D}}\left(\frac{M_{i}}{D_{i}}\right)^{1+\varphi_{i}^{C}}
$$

Para calibrar a equação (1) convém partir das condições marginais para maximização de lucro na produção setorial. A igualdade entre receita e custo marginal com relação a $F_{j f}$ é dada pela equação (46), e (47) decorre de (1).

$$
\begin{gathered}
W_{i f}=P_{j}^{V} \alpha_{j f} F_{i f}^{-\rho_{j}-1} \Omega_{j}\left[\sum_{f \in F C T} \alpha_{j f} F_{j f}^{-\rho_{j}}\right]^{\frac{-1}{\rho_{j}}-1} \\
\Omega_{j}=X_{j}\left[\sum_{f} \alpha_{j f} F_{j f}^{-\rho_{j}}\right]^{\frac{1}{\rho_{j}}}
\end{gathered}
$$


Tabela 3: Principais elasticidades utilizadas no modelo CGE

\begin{tabular}{|c|c|c|c|}
\hline Setores & $\begin{array}{l}\text { Expoente da função } \\
\text { de Armington }\end{array}$ & $\begin{array}{c}\text { Expoente } \\
\text { da função CET }\end{array}$ & $\begin{array}{c}\text { Expoente da função } \\
\text { de produção CES }\end{array}$ \\
\hline Agropecuária & 2 & 0,5 & 0,35 \\
\hline Extrativa mineral & 0,5 & 0,2 & 0,5 \\
\hline Petróleo e gás & 0,5 & 0,2 & 0,3 \\
\hline Minerais não-metálicos & 0,5 & 1,32 & 0,5 \\
\hline Siderurgia & 1,2 & 0,9 & 0,5 \\
\hline Metalurgia de não-ferrosos & 1,2 & 0,5 & 0,3 \\
\hline Outros metalúrgicos & 1,2 & 1,32 & 0,5 \\
\hline Máquinas e tratores & 0,5 & 1,32 & 0,65 \\
\hline Material elétrico & 1,5 & 1,32 & 0,5 \\
\hline Equipamentos eletrônicos & 1,5 & 1,32 & 0,75 \\
\hline Autos, caminhões e ônibus & 1,5 & 1,32 & 0,45 \\
\hline Outros veículos e peças & 1,5 & 1,32 & 0,5 \\
\hline Madeira e mobiliário & 0,5 & 1,1 & 0,5 \\
\hline Papel e gráfica & 2 & 0,9 & 0,5 \\
\hline Indústria da borracha & 1,5 & 1,32 & 0,5 \\
\hline Elementos químicos & 0,25 & 1,32 & 0,35 \\
\hline Refino do petróleo & 0,5 & 1,32 & 0,5 \\
\hline Químicos diversos & 0,75 & 1,32 & 0,4 \\
\hline Farmácia e perfumaria & 0,25 & 1,32 & 0,4 \\
\hline Artigos de plástico & 0,75 & 1,32 & 0,4 \\
\hline Indústria têxtil & 1,5 & 1,32 & 0,65 \\
\hline Artigos do vestuário & 1,5 & 1,32 & 0,75 \\
\hline Fabricação de calçados & 1,5 & 1,1 & 0,75 \\
\hline Indústria do café & 0,75 & 0,4 & 0,5 \\
\hline Beneficiamento de produtos vegetais & 1,5 & 0,6 & 0,5 \\
\hline Abate de animais & 1,5 & 0,3 & 0,5 \\
\hline Indústria de laticínios & 1,5 & 1,32 & 0,5 \\
\hline Indústria de açúcar & 0,8 & 1,2 & 0,5 \\
\hline Fabricação de óleos vegetais & 1,25 & 0,3 & 0,5 \\
\hline Outros produtos alimentares & 1,25 & 0,9 & 0,5 \\
\hline Indústrias diversas & 1,25 & 1,32 & 0,5 \\
\hline Utilidades públicas & 0,5 & 0,2 & 0,25 \\
\hline Construção & 0,5 & 0,2 & 0,75 \\
\hline comércio & 0,75 & 0,25 & 0,75 \\
\hline Transporte & 0,25 & 0,25 & 0,5 \\
\hline Comunicação & 0,5 & 0,75 & 0,35 \\
\hline Aluguel & 0,25 & 0,25 & 0,35 \\
\hline Administração pública & 0,5 & 0,5 & 0,5 \\
\hline Outros serviços & 0,25 & 0,25 & 0,5 \\
\hline
\end{tabular}

Fonte: Para coluna 2, Tourinho et alii (2007). Para as 3 e 4, elaboração própria. 
Usando (47) em (46) e resolvendo para o parâmetro de distribuição, temos (48). ${ }^{23}$

$$
\alpha_{j f}=\left[\sum_{f \in F C T} \alpha_{j f} F_{j f}^{-\rho_{j}}\right] \frac{W_{j f} F^{\rho_{j}+1}}{P_{j}^{V} X_{j}}
$$

Em seguida impõe-se a normalização $\sum_{f} \alpha_{j f}=1$, obtendo (49).

$$
\sum_{f} \alpha_{j f}=1=\frac{1}{P_{j}^{V} X_{j}}\left[\sum_{f \in F C T} \alpha_{j f} F_{j f}^{-\rho_{j}}\right] \sum_{f} W_{j f} F_{j f}^{\rho_{j}+1}
$$

Portanto,

$$
\left[\sum_{f \in F C T} \alpha_{j f} F_{j f}^{\rho_{j}+1}\right]=\frac{P_{j}^{V} X_{j}}{\sum_{f} W_{j f} F_{j f}^{\rho_{j}+1}}
$$

Usando (50) em (48), obtém-se (51), que pode ser utilizada para calibrar $\alpha_{j f}$.

$$
\alpha_{j f}=\frac{W_{j f} F_{j f}^{\rho_{j}+1}}{\sum_{f} W_{j f} F_{j f}^{\rho_{j}+1}}
$$

Dados os valores para $\alpha_{j f}$, a equação (47) pode ser usada para calcular $\Omega_{j}$.

A calibração dos parâmetros da função que determina o vetor de consumo das famílias de cada classe de renda (equação 14) também é feita com base na SAM. Para cada classe de renda a taxa de poupança é a razão entre a poupança total e a renda da classe, e os parâmetros de distribuição são a razão entre o dispêndio nos vários itens e a renda da classe, deduzida da fração destinada à poupança.

\subsection{Solução do modelo}

O modelo completo é um sistema de equações lineares e não-lineares onde o número de variáveis endógenas é igual ao de equações. A existência do equilíbrio é garantida pelo processo de calibração, mas não há garantias de que ele seja único. Entretanto, a experiência prática com modelos deste tipo indica que a ocorrência de multiplicidade de equilíbrios não é um problema freqüente.

O modelo é implementado com uso do pacote GAMS (General Algebraic Modeling System), que permite especificar problemas de otimização na sua forma algébrica padronizada em uma linguagem de programação própria, descrita em Rosenthal (2007). Ele gera os códigos e tabelas que alimentam as rotinas de otimização, permitindo que elas sejam utilizadas sem necessidade de fazer um programa para produzilas. Este conjunto de características simplifica enormemente a implementação do modelo, facilitando e acelerando as etapas de testes e validação, e as modificações na sua especificação que eventualmente sejam necessárias, bem como a feitura das simulações.

Foi escolhida a rotina de otimização PATH, dentre aquelas disponíveis no GAMS para a solução deste tipo de problema. Ela utiliza um algoritmo de complementaridade para resolver este tipo de sistema, aproveitando as propriedades do sistema dual, e se revelou extremamente eficiente, precisa e estável para a solução deste modelo.

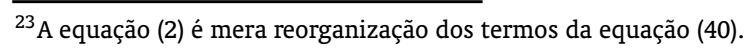




\section{SIMULAÇÕES DA REFORMA TRIBUTÁRIA}

As medidas da reforma tributária de 2003 são representadas nas simulações do modelo por modificações das alíquotas efetivas dos tributos relacionados nas tabelas 2 e 3 . Antes de passar à sua apresentação detalhada nas próximas seções, convém discutir algumas características gerais delas, e descrever as tabelas que utilizaremos para mostrar os resultados.

Em primeiro lugar, explicitamos a hipótese adotada quanto à destinação (ou origem) do aumento (redução) da arrecadação que elas podem provocar, pois isto afeta o impacto da medida através do seu efeito sobre a poupança pública e, consequentemente, a poupança total e o investimento agregado. Para as duas primeiras simulações descritas abaixo, que aumentam a carga tributária, supomos que o Governo utiliza o acréscimo de arrecadação para elevar sua poupança. Em particular, admite-se que ele não é utilizado para aumentar dispêndio do setor público, uma vez o Governo negou, explicitamente e de modo reiterado, que fosse este o objetivo da reforma tributária. ${ }^{24}$ Na terceira simulação, a da não-prorrogação da vigência da CPMF, que reduz a arrecadação, a hipótese é manutenção da poupança pública constante, pela redução das transferências do Governo em montante igual à redução da arrecadação.

Em segundo lugar, registramos que em todas as simulações o equilíbrio do balanço de pagamentos é mantido pela variação da taxa de câmbio, dado um determinado fluxo de capital externo (exógeno) que não depende do comportamento dos outros agregados macroeconômicos. ${ }^{25} \mathrm{~A}$ hipótese com relação ao câmbio, portanto, é que ele é flutuante, o que é consistente com o regime cambial brasileiro atual.

Em terceiro lugar, apontamos que em todas as simulações o PIB se mantém praticamente constante, devido à hipótese de pleno emprego implícita na formulação do modelo. Como as medidas tributárias afetam a capacidade produtiva setorial apenas indiretamente, a produção agregada não aumenta de modo significativo. Isto ajuda a destacar os efeitos setoriais da reforma tributária, pois permite identificar mais claramente os setores que são favorecidos e aqueles que são prejudicados por ela, enfatizando os efeitos qualitativos das medidas tributárias. Além disto, como o índice de preços é o numerário do modelo, ${ }^{26}$ e as variações de preços dos bens que ocorrem nas simulações são variações de preços relativos, o efeito das medidas tributárias sobre o bem estar do consumidor de cada classe de renda pode ser medido pela variação de sua renda.

Em quarto lugar, como existe interação entre os impostos, já que alguns entram na base de arrecadação de outros, e todas as equações do modelo são encadeadas, é importante explicitar em detalhes a estrutura (futura) da economia, especialmente na sua dimensão tributária. Para fazer isto, organizamos as simulações de modo a refletir a ordem cronológica da implantação das diversas medidas, utilizando como cenário de referência para avaliação de cada uma delas a configuração da economia após a implantação das que a antecederam. Assim, na primeira simulação as alíquotas relativas à contribuição sobre valor adicionado e imposto indireto são alteradas. A segunda simulação toma como referência o cenário resultante da primeira, e simula a incidência das contribuições sobre as importações, alterando a alíquota dos imposto sobre o valor adicionado sobre as importações. Finalmente, na terceira e última simulação, a alíquota efetiva dos outros impostos sobre faturamento é reduzida para representar a eliminação da CPMF. Esta última simulação tomou como referência o cenário resultante da segunda simulação porque quando ela foi implementada os efeitos das duas primeiras medidas já haviam se

\footnotetext{
${ }^{24} \mathrm{~A}$ hipótese quanto à destinação do aumento de arrecadação não afeta significativamente o resultado para estas duas primeiras simulações, porque o seu valor é uma proporção pequena da receita tributária total.

${ }^{25}$ Maldonado et alii (2007) mostram como o modelo deve ser alterado para que o fluxo de capital estrangeiro seja tratado como uma variável endógena. Eles analisam os impactos na economia nacional da adesão aos acordos de livre comércio atualmente em consideração.

${ }^{26} \mathrm{~A}$ necessidade de eleger um numerário se deve à estrutura dos modelos de equilíbrio geral, que só fornecem indicações quanto à variação dos preços relativos. Assim, os aumentos de preços de alguns bens e serviços acabam compensados, no índice, pelas reduções de preços de outros, o que permite identificar com clareza as mudanças de preços relativos produzidas pela reforma tributária.
} 
incorporado à configuração da economia. Portanto, a terceira simulação apresenta os resultados da implantação de todas as medidas consideradas. ${ }^{27}$

Finalmente, convém observar que, apesar desta versão do modelo ter sido formulada de modo a permitir a análise dos impactos distributivos das políticas tributárias, esta característica não foi explorada nas simulações aqui apresentadas, porque eles não se revelaram significativos para as medidas aqui simuladas. Em consequência, os resultados apresentados na próxima seção são da versão do modelo que não discrimina o consumo das famílias por classe de renda, e portanto supõe que há apenas uma família representativa cuja renda é igual à renda familiar média. ${ }^{28}$

Para cada simulação descrevemos inicialmente o seu impacto macroeconômico agregado e, em seguida, os impactos setoriais.

\subsection{A Eliminação da Cumulatividade da COFINS}

A lei ordinária 10.833 de 29/12/2003 transformou a COFINS em uma contribuição incidente sobre o valor adicionado, mas o fez em apenas em alguns setores, mantendo a tributação cumulativa para os setores restantes, como indicado na Tabela 4 . De fato, o conjunto de setores atingidos pela lei representa apenas $36,6 \%$ do PIB. Neles, a alíquota nominal passou de 3\% (sobre o faturamento) para 7,6\% (sobre o valor adicionado). ${ }^{29}$

Tabela 4: Tributação setorial da COFINS considerada no exercício, segundo a lei 10.833

\begin{tabular}{|c|c|c|}
\hline & & [\%do PIB] \\
\hline Setores & Analítico & Subtotal \\
\hline Setores que foram mantidos por lei no regime de tributação sobre faturamento & & 25,8 \\
\hline Refinarias, produtores de medicamentos e de veículos & 4,6 & \\
\hline Instituições financeiras, operadoras de planos de saúde, e empresas de telecomunicações & 21,2 & \\
\hline Setores isentos & & 34,3 \\
\hline Administração pública, aluguéis e transporte aéreo & 34,3 & \\
\hline Setores aqui mantidos com tributação sobre faturamento por opção metodológica* & & 3,3 \\
\hline $\begin{array}{l}\text { Extrativa mineral, equipamentos eletrônicos, químicos diversos, } \\
\text { artigos de plástico, fabricação de calçados e outros produtos alimentares }\end{array}$ & 3,3 & \\
\hline Setores que passaram a serem tributados pelo valor adicionado & & 36,6 \\
\hline Serviços industriais de utilidade pública, construção civil e comércio & 20,6 & \\
\hline Agropecuária e extração de petróleo & 5,2 & \\
\hline Demais setores da indústria de transformação não inclusos nas categorias anteriores & 10,8 & \\
\hline
\end{tabular}

Para simular esta alteração tributária no modelo é necessário inferir seu impacto nas alíquotas efetivas. Para fazê-lo, aproveitamos os resultados observados quando da transformação da base de incidência do PIS, de faturamento para valor adicionado, que foi anterior a 2003, e pode ser interpretada

\footnotetext{
${ }^{27} \mathrm{O}$ modelo não captura o impacto positivo sobre o crescimento econômico que poderia ocorrer devido aumento da eficiência microeconômica da economia que se poderia esperar da implementação destas medidas tributárias.

${ }^{28} \mathrm{~A}$ eventual extrapolação desta simplificação para a análise de outras políticas públicas não deve ser feita sem uma análise cuidadosa dos detalhes da política considerada e da estrutura do modelo.

${ }^{29}$ Note-se que os setores que são tributados com base no valor adicionado utilizam insumos de setores que permaneceram com tributação sobre o faturamento. Portanto, mesmo nos setores incluídos na alteração tributária, a cumulatividade continua a existir embora em um grau menor.
} 
Tabela 5: Alíquotas do COFINS nos setores afetados pela reforma tributária

\begin{tabular}{|l|c|c|c|c|c|}
\hline \multicolumn{1}{|c|}{ Setor } & \multicolumn{3}{|c|}{ Alíquota efetiva sobre: } & $\begin{array}{c}\text { Razão } \\
\text { Valor adicionado/ } \\
\text { faturamento }\end{array}$ & $\begin{array}{c}\text { Razão } \\
\text { exportações/ } \\
\text { faturamento }\end{array}$ \\
\cline { 2 - 6 } & Faturamento & $\begin{array}{c}\text { Valor adicionado } \\
\text { preços mercado }\end{array}$ & $\begin{array}{c}\text { Valor adicionado } \\
\text { custo de fatores }\end{array}$ & 55 & 8 \\
\hline Agropecuária & 0,18 & 0,45 & 0,49 & 81 & 12 \\
\hline Petróleo e gás & 0,31 & 0,43 & 0,45 & 34 & 16 \\
\hline $\begin{array}{l}\text { Indústria } \\
\text { de Transformação }\end{array}$ & 1,43 & 4,41 & 6,29 & 54 & - \\
\hline Utilidades públicas & 2,60 & 7,43 & 9,73 & 55 & - \\
\hline Construção civil & 0,80 & 2,01 & 2,08 & 55 & 1 \\
\hline Comércio & 0,39 & 8,23 & 11,44 & 59 & 10 \\
\hline Média & 1,30 & 3,83 & 5,08 & & \\
\hline
\end{tabular}

${ }^{1}$ Alíquota efetiva, neste caso, é calculada sobre a base tributária líquida de impostos indiretos, ou seja, sobre o valor adicionado a custo de fatores, deduzidos o dispêndio com pagamento do PIS e do COFINS.

${ }^{2}$ Os dados apresentados como referentes à indústria de transformação são de fato a média dos valores para todos os setores que a compõe, na nossa desagregação setorial. As simulações, entretanto, contemplaram variações diferenciadas para cada um destes setores.

Fonte: Elaboração própria.

como um experimento controlado da medida adotada por ocasião da reforma tributária. Utilizando os resultados observados naquela ocasião, calculamos a redução proporcional da alíquota do tributo sobre faturamento que é necessária para traduzir no modelo a sua transformação em tributo sobre valor adicionado. Estas novas alíquotas foram inseridas no modelo, um novo equilíbrio foi calculado, e a elasticidade daí inferida foi utilizada para calibrar a variação da alíquota do imposto indireto, por atividade, que simularia os efeitos de medida análoga na COFINS. ${ }^{30}$

As alíquotas efetivas assim obtidas estão sintetizadas na Tabela 5, onde se verifica que a alíquota sobre valor adicionado é, em média, cerca de 2,9 vezes aquela sobre faturamento, e que aquele multiplicador varia bastante entre os setores, devido a diferenças na razão entre o VA e as exportações, e o faturamento.

\section{RESULTADOS AGREGADOS}

A medida contemplada nesta seção provoca um aumento na carga fiscal total de $0,2 \%$ do PIB, e uma redução do PIB a custo de fatores de $0,4 \%$. A arrecadação da contribuição sobre o valor adicionado $(C V A)$, que reflete a arrecadação da nova COFINS, atinge $1,6 \%$ do PIB, valor que supera em $0,2 \%$ do PIB a redução da tributação indireta $(I N D T A X)$ devido redução da arrecadação da COFINS sobre o faturamento. Conclui-se, portanto, que a alíquota da nova contribuição poderia ter sido menor do que a adotada (7,6\%), caso se pretendesse de fato manter estável a arrecadação com aquela contribuição. Este aumento líquido de arrecadação se transfere para a arrecadação total, e ocorre apesar de setores que correspondem a $65,3 \%$ do PIB continuarem sob o regime cumulativo da sistemática anterior. ${ }^{31}$

Como o câmbio mantém-se praticamente estável, o valor total importado ou exportado, e o saldo comercial, não são afetados de modo significativo, provavelmente porque a alteração tributária atinge a competitividade das importações e exportações de modo simétrico. Além disto, a hipótese adotada para

\footnotetext{
${ }^{30}$ Este cálculo está detalhado em Silva et alii (2005).

${ }^{31} \mathrm{~A}$ arrecadação das outras categorias de impostos, que não são atingidas pelas alterações tributárias contempladas nesta seção, não sofre alteração significativa.
} 
o fechamento macroeconômico do modelo, já discutida anteriormente, exige que o saldo em transações correntes se mantenha constante, e isto condiciona as eventuais variações no comércio internacional.

\section{RESULTADOS SETORIAIS}

A Tabela 6 apresenta o impacto sobre os setores consolidados da alteração da base de incidência da COFINS. Discutimos abaixo os dados mais relevantes de cada uma de suas colunas.

Tabela 6: Efeitos setoriais da modificação na COFINS

\begin{tabular}{|c|c|c|c|c|c|c|c|}
\hline \multirow[b]{2}{*}{ Setor } & \multirow[b]{2}{*}{$\begin{array}{l}\text { Arrecadação } \\
\text { da COFINS }\end{array}$} & \multirow[b]{2}{*}{$\begin{array}{l}\text { Preço recebido } \\
\text { pelo produtor }\end{array}$} & \multirow[b]{2}{*}{$\begin{array}{c}\text { Preço pago } \\
\text { pelo consumidor }\end{array}$} & \multicolumn{4}{|c|}{ [variações percentuais] } \\
\hline & & & & $\begin{array}{c}\text { Produção } \\
\text { doméstica } \\
\text { bruta }\end{array}$ & $\begin{array}{c}\text { Valor } \\
\text { adicionado }\end{array}$ & $\begin{array}{c}\text { Valor das } \\
\text { importações } \\
\text { (em US\$) }\end{array}$ & $\begin{array}{c}\text { Valor das } \\
\text { exportações } \\
\text { (em US\$) }\end{array}$ \\
\hline & (1) & (2) & (3) & (4) & (5) & (6) & (7) \\
\hline Agropecuária & 25,20 & 0,60 & 0,50 & $-0,58$ & $-0,85$ & 0,07 & $-0,74$ \\
\hline Extrativa mineral & 0,00 & $-0,10$ & $-0,40$ & 0,45 & 0,12 & 0,03 & 0,54 \\
\hline Petróleo e gás & 99,64 & 0,00 & 0,00 & 0,02 & $-0,24$ & $-0,08$ & 0,07 \\
\hline Ind. de transformação & 24,72 & 0,32 & 0,23 & 0,32 & $-0,43$ & 0,20 & 0,09 \\
\hline Utilidades públicas & 49,29 & 2,20 & 2,20 & $-1,18$ & $-1,52$ & $-0,17$ & 0,00 \\
\hline Construção & 0,00 & 0,00 & 0,00 & 1,19 & 0,87 & 1,12 & 0,00 \\
\hline Comércio & $-5,66$ & $-0,50$ & $-0,40$ & $-0,08$ & $-0,52$ & $-0,48$ & 0,16 \\
\hline Transporte & 0,00 & $-0,20$ & $-0,20$ & $-0,16$ & $-0,63$ & $-0,27$ & 0,03 \\
\hline Comunicação & 0,00 & $-0,20$ & $-0,20$ & $-0,14$ & $-0,48$ & $-0,35$ & 0,20 \\
\hline Aluguel & 0,00 & $-0,20$ & $-0,20$ & $-0,25$ & $-0,50$ & 0,00 & 0,00 \\
\hline Adm. pública & 0 & $-0,3$ & $-0,3$ & 0 & $-0,53$ & $-0,19$ & 0,31 \\
\hline Outros serviços & 0,00 & $-0,20$ & $-0,20$ & $-0,10$ & $-0,56$ & $-0,18$ & 0,04 \\
\hline Total & 13,41 & & & & $-0,43$ & $-0,18$ & 0,04 \\
\hline
\end{tabular}

${ }^{1}$ Valor adicionado a custo de fatores, deduzidos os outros impostos sobre a produção.

Fonte: Elaboração própria.

Em cada setor, o impacto na arrecadação da COFINS (coluna (1)) depende do seu efeito sobre a alíquota efetiva da contribuição, e sobre o valor adicionado. De um modo geral, os setores em que a receita aumenta mais são aqueles em que o valor adicionado é uma fração maior do faturamento bruto setorial do que na média da economia. Por exemplo, a receita nos setores que mantiveram a alíquota de $3 \%$ sobre o faturamento praticamente não se altera, mas na indústria de transformação e nos serviços industriais de utilidade pública ela aumenta respectivamente $24,7 \%$ e $49,3 \%$.

O impacto nos preços se deve ao efeito sobre os custos, que tem não só um componente direto, fruto do efeito da alteração tributária no próprio setor, mas também um efeito indireto, devido à variação nos custos dos insumos. Este impacto se distribui entre variações do preço recebido pelos produtores e pelos consumidores, mas o modo como o impacto se reparte entre eles depende das elasticidades implícitas no próprio modelo. No entanto, quando se comparam os setores, verifica-se que na maioria deles o efeito nos preços ao consumidor é similar àquele nos preços ao produtor, ou seja, o impacto da medida se distribui igualmente entre produtores e consumidores, como se verifica nas colunas 2 e 3 . 0 aumento mais importante nos preços ocorre nos serviços industriais de utilidade pública $(2,20 \%)$, e a maior redução ocorre no setor de comércio $(-0,5 \%)$.

O efeito sobre a produção bruta e o valor adicionado setorial (colunas 4 e 5 , respectivamente) é modesto, como se poderia esperar com base nas observações feitas anteriormente quanto à especificação do modelo. Apesar disto, ele é um indicador tanto do sinal do impacto quanto de sua força relativa. 0 setor que tem produção mais prejudicada é o de serviços industriais de utilidade pública, com redução de $1,18 \%$, enquanto na indústria de transformação ela aumentaria $0,3 \%$.

$\mathrm{O}$ valor adicionado a custo de fatores se reduz na maioria dos setores porque o repasse do aumento de carga tributária para preços é dificultado pela oferta de produtos importados a preços internados que 
não são afetados pela mudança tributária, e ele acaba se transformando em perda de remuneração dos fatores na maioria dos setores industriais. ${ }^{32}$ Esta redução ocorre em todos os setores, exceto na construção civil e extrativa mineral, onde ele aumenta respectivamente $0,9 \%$ e $0,1 \%$. As maiores reduções ocorreram nos serviços de utilidade pública $(1,5 \%)$, e na indústria de transformação $(0,4 \%)$.

Examinando o comércio internacional por setores (colunas 6 e 7), verifica-se que as importações se reduzem marginalmente na maioria deles, enquanto as exportações pouco se alteram. ${ }^{33}$

O nível de desagregação apresentado na Tabela 6 não é o máximo permitido pelo modelo, que contempla 39 setores. Examinando em mais detalhe os sub-setores da indústria de transformação verificase que o valor adicionado a custo de fatores se reduz na maioria deles, mas aumenta para minerais não-metálicos, siderurgia, metalurgia de não-ferrosos, outros metalúrgicos, máquinas e tratores, equipamentos eletrônicos, automóveis caminhões e ônibus, outros veículos e peças, e fabricação de calçados. Os setores aonde a perda relativa é maior são os de papel e gráfica, beneficiamento de produtos vegetais e indústria do açúcar.

\subsection{O PIS/PASEP e o COFINS sobre as importações}

A segunda simulação visa avaliar os impactos da Emenda Constitucional $n^{\circ} 42$, de 19/12/2003, que permitiu a cobrança de contribuições sociais sobre produtos importados, e da lei ordinária $\mathrm{n}^{\circ} 10865$ de 30/04/2004 que instituiu e regulamentou a cobrança do PIS/PASEP e da COFINS sobre as importações de bens e serviços. ${ }^{34}$ Estas medidas se refletem no modelo nos preços internados dos bens importados, que passa a ser afetado por aquelas contribuições, e não apenas pelo preço internacional, taxa de câmbio, e tarifa de importação, como especificado na equação (20).

Para calcular a alíquota efetiva destes outros tributos é necessário fazer uma hipótese que permita extraí-las das alíquotas nominais daquelas contribuições. Para isto admitimos que a relação atualmente existente entre as alíquotas nominais e efetivas do imposto de importação se mantém também para aquelas o PIS/PASEP e COFINS sobre importações. ${ }^{35}$ Deste modo considera-se de modo adequado a manutenção dos regimes aduaneiros especiais, onde o importador é isento tanto do imposto de importação quanto das contribuições.

Para a maioria dos bens as alíquotas nominais do PIS/PASEP e COFINS sobre as importações foram fixadas em valor idêntico ao das alíquotas sobre os bens domésticos, respectivamente $1,7 \%$ e 7,6\%. Os setores listados a seguir, acompanhados das respectivas tarifas, são exceções àquela regra: produtos farmacêuticos (2,1\% e 9,9\%), artigos de perfumaria (2,2\% e $10,3 \%)$, veículos ( $2 \%$ e $9,6 \%)$, cervejas e refrigerantes $(2,5 \%$ e $11,9 \%)$, e gasolina $(5,1 \%$ e $23,4 \%)$. O impacto destas mudanças na cunha fiscal das importações é reportado na Tabela 7, onde se verifica que os bens importados mais afetados são os derivados de petróleo, fármacos e perfumarias, margem de comércio, transportes, comunicações e outros serviços.

Este exercício teve como cenário de referência aquele produzido pela simulação descrita na seção anterior, que caracteriza a economia funcionando já com a COFINS incidindo sobre valor adicionado, e é a mais próxima possível da economia real quando da implantação da medida aqui considerada.

\footnotetext{
${ }^{32}$ Esta restrição é relaxada na próxima seção, onde se discute o impacto da incidência do COFINS e do PIS/PASEP sobre as importações.

33É necessário ter cautela na interpretação das variações percentuais das importações e exportações na Tabela 7 porque em alguns a base de comparação é muito pequena, o que induz a ocorrência de valores elevados para a variação proporcional correspondentes a variações absolutas relativamente pequenas.

${ }^{34}$ O exercício de simulação realizado nesta seção leva em conta que a lei no 10865 reverteu em parte os efeitos da lei no. 10833 , e manteve o setor de construção civil e de transporte aéreo no regime de tributação cumulativa do COFINS.

${ }^{35} \mathrm{~A}$ base de dados com as relações entre alíquotas efetivas e nominais do imposto de importação para vários setores foi fornecida pela Coordenação de Comércio Exterior e Política Comercial da Diretoria de Estudos Macroeconômicos do IPEA. Levamos também em conta no cálculo das tarifas efetivas que a base tributária das contribuições sobre importações inclui ainda o ICMS, o PIS/PASEP e o COFINS.
} 
Tabela 7: Cunha fiscal na importação, devida à incidência da tarifa, PIS/PASEP e COFINS

\begin{tabular}{|c|c|c|c|}
\hline & & & [em \% do valor da importação] \\
\hline & Base & Experimento & Diferença \\
\hline Agropecuária & 2,04 & 2,94 & 0,9 \\
\hline Extrativa mineral & 1,47 & 5,21 & 3,7 \\
\hline Extração de petróleo e gás & 0,00 & 4,85 & 4,8 \\
\hline Minerais não-metálicos & 6,50 & 10,83 & 4,3 \\
\hline Siderurgia & 4,37 & 11,71 & 7,3 \\
\hline Metalurgia de não-ferrosos & 3,95 & 11,42 & 7,5 \\
\hline Outros metalúrgicos & 9,42 & 17,28 & 7,9 \\
\hline Máquinas e tratores & 8,51 & 15,19 & 6,7 \\
\hline Material elétrico & 7,70 & 14,90 & 7,2 \\
\hline Equipamentos eletrônicos & 4,93 & 12,07 & 7,1 \\
\hline Autos, caminhões e ônibus & 9,77 & 13,76 & 4 \\
\hline Outros veículos e peças & 5,77 & 8,72 & 3 \\
\hline Madeira e mobiliário & 8,25 & 8,3 & 0,1 \\
\hline Papel e gráfica & 4,49 & 11,66 & 7,2 \\
\hline Indústria da borracha & 7,75 & 15,81 & 8,1 \\
\hline Elementos químicos & 4,60 & 8,31 & 3,7 \\
\hline Refino do petróleo & 3,58 & 30,68 & 27,1 \\
\hline Químicos diversos & 5,39 & 12,91 & 7,5 \\
\hline Farmácia e perfumaria & 1,98 & 14,45 & 12,5 \\
\hline Artigos de plástico & 10,21 & 18,24 & 8 \\
\hline Indústria têxtil & 11,71 & 11,79 & 0,1 \\
\hline Artigos do vestuário & 19,88 & 19,97 & 0,1 \\
\hline Fabricação de calçados & 8,93 & 9,04 & 0,1 \\
\hline Indústria do café & 9,39 & 10,32 & 0,9 \\
\hline Beneficiamento de produtos vegetais & 3,01 & 3,97 & 1 \\
\hline Abate de animais & 2,74 & 7,38 & 4,6 \\
\hline Indústria de laticínios & 3,94 & 8,77 & 4,8 \\
\hline Indústria de açúcar & 8,50 & 9,43 & 0,9 \\
\hline Fabricação de óleos vegetais & 5,46 & 9,93 & 4,5 \\
\hline Outros produtos alimentares & 5,39 & 13,32 & 7,9 \\
\hline Indústrias diversas & 7,76 & 7,85 & 0,1 \\
\hline Serviços industriais de util. pública & 0,00 & 0,00 & 0,0 \\
\hline Construção civil & 0,00 & 0,00 & 0,0 \\
\hline Comércio & 1,26 & 11,62 & 10,4 \\
\hline Transportes & 0,02 & 10,6 & 10,6 \\
\hline Comunicações & 1,18 & 13,54 & 12,4 \\
\hline Aluguel de imóveis & 0,00 & 0,00 & 0,0 \\
\hline Administração pública & 1,09 & 1,09 & 0,0 \\
\hline Outros serviços & 0,01 & 10,54 & 10,5 \\
\hline
\end{tabular}

Fonte: Elaboração própria. 


\section{RESULTADOS AGREGADOS}

A adoção do PIS/PASEP e do COFINS sobre importações produz uma arrecadação igual 1,0\% do PIB, mas a arrecadação total aumenta em apenas $0,6 \%$ do PIB. Ela não afeta a capacidade produtiva setorial e tem pequeno impacto no PIB a preços de mercado, mas reduz o PIB a preços de fatores em $1,2 \%$.

O câmbio se valoriza (a taxa de câmbio se reduz) em $1,2 \%$, para manter constante o resultado da conta corrente do balanço de pagamentos frente à alteração tributária que aumenta a proteção ao produto domestico. Esta valorização interage com o aumento da cunha fiscal nas importações, e produz uma redução do preço internado do bem importado, que é responsável por um aumento de $7,3 \%$ da quantidade total importada. A valorização do câmbio também causa uma redução de $0,47 \%$ na quantidade exportada total.

\section{RESULTADOS SETORIAIS}

A Tabela 8 apresenta os resultados setoriais da incidência do PIS/PASEP e COFINS sobre as importações. As colunas 1 e 2 mostram que o preço da maioria dos bens se eleva, com exceção de utilidade pública, comunicação, aluguel, e administração pública. Para petróleo e gás, comércio e outros serviços, apenas o preço médio recebido pelo produtor cai. A elevação de preços na oferta doméstica é consequência do aumento do preço internado das importações, pois ela resulta da combinação do bem produzido no país com o bem importado, e o seu preço é uma agregação dos preços destes dois bens. Esta elevação de preços também atinge os insumos e o custo da produção doméstica destes mesmos bens, realimentando a elevação de preços inicial.

A produção bruta é negativamente afetada em praticamente todos os setores, como se verifica na coluna 3, com exceção dos seguintes setores: construção civil $(+3,7 \%)$, extrativa mineral $(+0,1 \%)$, petróleo e gás $(+0,7 \%)$, e indústria de transformação $(+0,2 \%)$. 0 efeito sobre o valor adicionado setorial (coluna 4) acompanha, de um modo geral, o efeito sobre o produto, destacando-se o efeito positivo sobre o setor de construção $(2,92 \%)$ e o efeito negativo sobre o setor de transporte $(-2,5 \%)$.

Examinando em mais detalhe o impacto na indústria de transformação da incidência do COFINS e do PIS/PASEP sobre as importações, verifica-se que a produção industrial aumenta em $0,21 \%$, mas tem quedas expressivas nos setores farmácia e perfumaria $(-2,7 \%)$ e fabricação de calçados $(-10,4 \%)$, que são compensadas por alguns aumentos significativos, dentre os quais se destaca o de minerais não metálicos $(2,3 \%)$. O valor adicionado da indústria de transformação, entretanto, declina em $1,2 \%$. Os resultados setoriais quanto ao comércio exterior confirmam os resultados agregados discutidos anteriormente, e na indústria de transformação como um todo há um aumento de 4,6\% nas importações e uma redução de $2,6 \%$ nas exportações. As importações aumentam em mais de $3 \%$ em vários subsetores da indústria de transformação, enquanto as exportações se reduzem em todos os sub-setores, e em vários deles em mais do que $3 \%$. Tanto os preços ao produtor quanto ao consumidor aumentam em quase todos os sub setores da indústria de transformação, com destaque para metalurgia de nãoferrosos ( $1,1 \%$ e $2,1 \%)$, refino de petróleo $(1,0 \%$ e $3,1 \%)$, químicos diversos $(1,0 \%$ e $1,7 \%)$ e artigos de plástico $(1,0 \%$ e $1,5 \%)$.

\subsection{Extinção da CPMF}

A não prorrogação do prazo de validade da CPMF em final de 2007 correspondeu à eliminação da sua cobrança. No modelo isto foi simulado com a redução da alíquota do imposto indireto sobre as atividades em um montante que reflete o impacto direto calculado pelo próprio governo daquela medida sobre o total de arrecadação daquele imposto. Como a variável que o representa (INDTAX) inclui o total da arrecadação do PIS, COFINS, CPMF, e outros tributos indiretos, para excluir a parcela representada pela arrecadação da CPMF, reduzimos a alíquota dos impostos indiretos (TX) no modelo em $38 \%$, que é a participação da arrecadação daquela contribuição na arrecadação total de impostos indiretos. 
Tabela 8: Efeitos setoriais da adoção do PIS/PASEP e COFINS sobre importações

\begin{tabular}{|l|c|c|c|c|c|c|}
\hline & \multicolumn{9}{|c|}{} & \multicolumn{2}{c|}{ [variações percentuais] } \\
\hline Setor & $\begin{array}{c}\text { Preço médio } \\
\text { recebido pelo } \\
\text { produtor }\end{array}$ & $\begin{array}{c}\text { Preço médio } \\
\text { pago pelo } \\
\text { consumidor }\end{array}$ & $\begin{array}{c}\text { Produção } \\
\text { doméstica bruta }\end{array}$ & $\begin{array}{c}\text { Valor } \\
\text { adicionado }{ }^{1}\end{array}$ & $\begin{array}{c}\text { Valor das } \\
\text { importações }\end{array}$ & $\begin{array}{c}\text { Valor das } \\
\text { importações }\end{array}$ \\
\hline Agropecuária & $(1)$ & $(2)$ & $(3)$ & $(4)$ & $(5)$ & $(6)$ \\
\hline Extrativa mineral & 0,10 & 0,20 & $-1,25$ & $-1,82$ & 0,78 & $-1,93$ \\
\hline Petróleo e gás & 0,60 & 2,81 & 0,10 & $-0,75$ & 4,40 & $-0,30$ \\
\hline Ind. de transformação & $-0,30$ & 0,80 & 0,76 & 0,29 & 3,71 & 0,58 \\
\hline Utilidades públicas & 0,46 & 1,31 & 0,21 & $-1,17$ & 4,55 & $-2,56$ \\
\hline Construção & $-0,49$ & $-0,59$ & $-0,41$ & $-1,33$ & $-0,14$ & 0,00 \\
\hline Comércio & 0,10 & 0,10 & 3,66 & 2,92 & 4,27 & 0,00 \\
\hline Transporte & $-0,10$ & 0,10 & $-0,48$ & $-1,89$ & 2,49 & $-0,80$ \\
\hline Comunicação & 0,70 & 0,80 & $-0,91$ & $-2,49$ & 6,86 & $-1,40$ \\
\hline Aluguel & $-0,40$ & $-0,20$ & $-0,64$ & $-1,53$ & 4,81 & $-1,25$ \\
\hline Adm. pública & $-0,40$ & $-0,40$ & $-0,91$ & $-1,34$ & 0,00 & 0,00 \\
\hline Outros serviços & $-1,2$ & $-1,2$ & 0,00 & $-1,90$ & $-0,04$ & $-0,04$ \\
\hline TOTAL & $-0,80$ & 0,00 & $-0,32$ & $-1,77$ & 7,30 & $-0,47$ \\
\hline
\end{tabular}

${ }^{1}$ Valor adicionado a custo de fatores, deduzidos os outros impostos sobre a produção.

Fonte: Elaboração própria.

Admitimos que esta redução da arrecadação é compensada com uma redução de consumo do governo, o que permite que sejam mantidos constantes a poupança e o endividamento interno do governo.

\section{RESULTADOS AGREGADOS}

A eliminação da CPMF produz uma queda insignificante no PIB a preços de mercado, mas causa um aumento de $1,9 \%$ do PIB a custo de fatores, devido a uma redução de $38,4 \%$ na arrecadação dos impostos indiretos (INDT AX) e um aumento na arrecadação do imposto e da contribuição sobre valor adicionado $(V A T e C V A)$ de respectivamente, $2,7 \%$ e $2,3 \%$. Também aumentam a arrecadação de seguridade social $(2,3 \%)$ e o imposto de renda sobre pessoa física $(2,2 \%)$ devido ao aumento da renda agregada. Estes aumentos de receita tributária se contrapõem à perda de receita direta da eliminação da CPMF, fazendo com que a perda líquida seja da ordem de R $\$ 20$ bilhões, inferior ao esperado impacto direto de R\$ 40 bilhões. Portanto, os resultados deste exercício sugerem que a redução da carga tributária gera renda adicional que, quando tributada pelos impostos restantes, compensa a redução inicial de tributos. O câmbio se valoriza em $1,0 \%$, e o saldo comercial se reduz, fruto de um aumento de $1,0 \%$ tanto nas importações quanto nas exportações.

\section{RESULTADOS SETORIAIS}

Os resultados setoriais de eliminação da CPMF são apresentados na Tabela 9. O preço médio ao produtor (coluna 1) cai na maioria dos setores, exceto agropecuária, comércio, aluguéis e administração pública, onde ele se eleva em cerca de $1 \%$. Os preços ao consumidor (coluna 2 ) têm um comportamento similar àquele dos preços ao produtor. Na indústria de transformação os preços ao produtor e ao consumidor apresentam variação negativa de $1,09 \%$ e $0,96 \%$, respectivamente, seguindo a tendência dos outros setores. Dentre as alterações na produção bruta dos vários setores (coluna 3), destacam-se o 
aumento de $1,5 \%$ nas comunicações e a redução de $4,4 \%$ na construção civil e $0,8 \%$ na indústria de transformação.

No comércio internacional (colunas 5 e 6) destacam-se o expressivo aumento das importações de bens agropecuários (5\%) e a estabilidade das exportações.

O principal impacto na indústria de transformação ocorre nas contas do setor externo, onde o valor das suas importações cai $0,2 \%$, e o das suas exportações aumenta $0,6 \%$. Dentre os sub-setores, verificase que a maioria sofre impacto similar ao do agregado, sendo que o que apresenta a maior incremento das importações é o de artigos de vestuário $(3,8 \%)$.

Tabela 9: Efeitos setoriais da eliminação da CPMF

\begin{tabular}{|c|c|c|c|c|c|c|}
\hline \multirow[b]{2}{*}{ Setor } & \multicolumn{6}{|c|}{ [variações percentuais] } \\
\hline & $\begin{array}{l}\text { Preço médio } \\
\text { recebido pelo } \\
\text { produtor }\end{array}$ & $\begin{array}{l}\text { Preço médio } \\
\text { pago pelo } \\
\text { consumidor }\end{array}$ & $\begin{array}{c}\text { Produção } \\
\text { doméstica } \\
\text { bruta }\end{array}$ & $\begin{array}{c}\text { Valor } \\
\text { adicionado }^{1}\end{array}$ & $\begin{array}{c}\text { Valor das } \\
\text { importações } \\
\text { (em US\$) }\end{array}$ & $\begin{array}{c}\text { Valor das } \\
\text { importações } \\
\text { (em US\$) }\end{array}$ \\
\hline & $(1)$ & $(2)$ & (3) & (4) & (5) & (6) \\
\hline Agropecuária & 0,79 & 0,79 & 1,00 & 2,90 & 4,98 & 0,14 \\
\hline Extrativa mineral & $-1,49$ & $-1,76$ & $-0,89$ & 1,09 & $-1,28$ & $-0,76$ \\
\hline Petróleo e gás & $-0,4$ & $-0,5$ & 0,58 & 2,38 & 1,00 & 0,5 \\
\hline Indústria de transformação & $-1,09$ & $-0,96$ & $-0,77$ & 1,93 & $-0,24$ & 0,59 \\
\hline Utilidades públicas & 0,98 & 0,89 & 0,45 & 2,40 & 1,54 & 0,00 \\
\hline Construção & $-0,50$ & $-0,50$ & $-4,37$ & $-2,49$ & $-4,04$ & 0,00 \\
\hline comércio & 0,20 & 0,20 & 0,8 & 3,14 & 1,91 & 0,58 \\
\hline Transporte & $-1,09$ & $-1,09$ & 1,41 & 3,86 & 1,82 & 1,44 \\
\hline Comunicação & $-0,40$ & $-0,40$ & 1,54 & 3,55 & 1,77 & 1,12 \\
\hline Aluguel & 1,01 & 1,01 & 1,08 & 2,88 & 0,00 & 0,00 \\
\hline Administração pública & 1,22 & 1,22 & $-1,89$ & 0,33 & $-0,72$ & $-2,9$ \\
\hline Outros serviços & $-0,61$ & $-0,60$ & 0,95 & 3,19 & 1,05 & 0,89 \\
\hline TOTAL & & & & 1,93 & 1,05 & 0,89 \\
\hline
\end{tabular}

Fonte: Elaboração própria.

O impacto da eliminação da CPMF sobre os salários dos diferentes tipos de mão-de-obra é bastante diferenciado, em contraste com os impactos salariais das duas simulações anteriores. Ele é descrito a seguir com base na SAM 2003, levando em conta que no modelo o fator trabalho é estratificado em seis tipos básicos, dependendo do grau de qualificação do trabalhador e da formalização de seu contrato de trabalho, como descrito nas três primeiras colunas na Tabela $10 .{ }^{36}$

Tabela 10: Efeito da eliminação da CPMF nos salários dos tipos de mão-de-obra

\begin{tabular}{|l|c|c|c|c|c|c|c|}
\hline Escolaridade & Qualificação & $\begin{array}{c}\text { Número de anos } \\
\text { na escola }\end{array}$ & Código & \multicolumn{3}{|c|}{$\begin{array}{c}\text { Variação salarial percentual } \\
\text { (por tipo de trabalhador) }\end{array}$} \\
\hline & & & & \multicolumn{2}{|c|}{ Formal (F) } & \multicolumn{2}{|c|}{ Informal (NF) } \\
\hline Primário & Baixa & 0 a 8 & (L) & (LF) & 2,67 & (LNF) & 5,56 \\
\hline Secundário & Média & 9 a 11 & (M) & (MF) & 2,48 & (MNF) & 2,22 \\
\hline Superior & Alta & Mais que 11 & (H) & (HF) & 2,16 & (HNF) & 3,25 \\
\hline
\end{tabular}

Fonte: Elaboração própria.

As duas últimas colunas da Tabela 10 mostram a variação porcentual do salário dos diversos tipos de mão-de-obra, e indicam que ele aumenta em todos os casos. Os trabalhadores mais beneficiados são

\footnotetext{
${ }^{36}$ A qualificação é caracterizada pela escolaridade formal do trabalhador, medida pelo número de anos na escola, e a formalização
} da relação trabalhista é medida pelo recolhimento da contribuição respectiva à Previdência Social. 
os de baixa qualificação não-formais, e os de alta qualificação formais, cuja remuneração aumenta em $5,6 \%$ e $3,3 \%$ respectivamente.

O efeito da eliminação da CPMF na renda do trabalho, mostrada na Tabela 11, depende da agregação para todos os setores do seu efeito sobre o salário e sobre a demanda de trabalho setorial, de cada tipo de trabalhador. As variações da renda não são iguais às de salário porque, apesar da oferta total de cada tipo de mão-de-obra ser mantida constante, há re-alocação da mão de obra entre setores. No cenário de referência os trabalhadores de alta qualificação ficam com $46,7 \%$ da renda agregada do trabalho, enquanto que os de média e baixa qualificação ficam com respectivamente $28,2 \%$ e $25,2 \%$ dela. Com a eliminação da CPMF a renda agregada do trabalho aumenta $1,8 \%$, e há uma redução da sua dispersão, pois a parcela dos trabalhadores de alta qualificação se reduz em $0,2 \%$, enquanto a dos trabalhadores de baixa e média qualificação aumenta respectivamente $0,1 \%$ e $0,06 \%$.

Tabela 11: Efeito da eliminação da CPMF nos salários dos tipos de mão-de-obra

\begin{tabular}{|l|c|c|c|c|c|c|c|c|}
\hline & Cenario & Total & \multicolumn{6}{|c|}{$\begin{array}{c}\text { Valor e Participação dos tipos de mão-de-obra } \\
\text { no rendimento total do trabalho }\end{array}$} \\
\hline & & & LF & LNF & MF & MNF & HF & HNF \\
\hline \multirow{2}{*}{$\begin{array}{l}\text { Renda do trabalho } \\
\text { (RS bilhões) }\end{array}$} & BASE & 509,717 & 78,507 & 49,809 & 112,695 & 30,791 & 209,859 & 28,056 \\
\cline { 2 - 9 } & S / CPMF & 519,023 & 80,168 & 50,992 & 114,813 & 31,604 & 212,663 & 28,783 \\
\hline $\begin{array}{l}\text { Participação por } \\
\text { tipo (\%) }\end{array}$ & BASE & 100 & 15,40 & 9,77 & 22,11 & 6,04 & 41,17 & 5,50 \\
\cline { 2 - 9 } & S / CPMF & 100 & 15,45 & 9,82 & 22,12 & 6,09 & 40,97 & 5,55 \\
\hline $\begin{array}{l}\text { Participação por } \\
\text { especialização (\%) }\end{array}$ & BASE & 100 & \multicolumn{2}{|c|}{25,17} & \multicolumn{2}{|c|}{28,15} & \multicolumn{2}{|c|}{46,68} \\
\cline { 2 - 9 } & S / CPMF & 100 & \multicolumn{2}{|c|}{25,27} & \multicolumn{2}{|c|}{28,21} & \multicolumn{3}{|c}{46,52} \\
\hline
\end{tabular}

Fonte: Elaboração própria.

As alterações salariais induzem mudanças na distribuição de renda que podem ser calculadas com auxílio da Tabela 12, que mostra o peso de cada tipo de mão-de-obra na composição da renda de cada classe. ${ }^{37}$ Nela se verifica, como se poderia esperar, que a maior parte da renda das famílias nas classes de renda mais baixa tem sua origem no trabalhado de baixa e média qualificação. Com estes dados pode-se calcular o efeito na renda das famílias de cada classe das alterações salariais indicadas na Tabela 10, que se revela aproximadamente uniforme ao longo das classes, igual a cerca de $2,0 \%$.

\section{CONCLUSÃO}

Este artigo avaliou o impacto econômico da transformação parcial da COFINS em uma contribuição sobre o valor adicionado, da incidência dos PIS/COFINS sobre as importações, que ocorreram em 2003, e da extinção da CPMF em 2007. O instrumento utilizado foi um modelo de equilíbrio geral aplicado (CGE) da economia brasileira em 2003, adaptado para simular os efeitos destas medidas. Os cenários resultam da solução do modelo com mudanças paramétricas que representam aquelas medidas, e refletem a interdependência setorial representada pela matriz insumo-produto, e o atendimento às restrições macroeconômicas agregadas.

Os resultados apresentados descrevem o equilíbrio macroeconômico e setorial da economia no caso da implantação daquelas medidas, e permite comparações com um cenário básico correspondente à situação observada no ano-base. Ao nível macro eles dizem respeito ao seu impacto sobre o produto, as contas públicas, o balanço de pagamentos e o câmbio, e sobre os salários e distribuição de renda. Ao

\footnotetext{
${ }^{37}$ Mostramos apenas o seu impacto distributivo direto das alterações salariais, pois efeito secundário resultante da mudança que ele provoca na distribuição do consumo entre diferentes bens não foi considerado nestas simulações, como indicado anteriormente.
} 
Tabela 12: Rendimentos do trabalho na composição da renda do trabalho das famílias, SAM 2003

\begin{tabular}{|c|c|c|c|c|c|c|c|c|c|c|}
\hline \multirow{3}{*}{$\begin{array}{c}\text { Classe } \\
\text { de renda }\end{array}$} & \multicolumn{2}{|c|}{ Limites de renda da classe } & \multirow{3}{*}{$\begin{array}{c}\text { Renda } \\
\text { da classe } \\
\text { (RS Bilhões de 2003) }\end{array}$} & \multirow{3}{*}{$\begin{array}{c}\text { Participação } \\
\text { da classe } \\
\text { (\%) }\end{array}$} & \multirow{2}{*}{\multicolumn{6}{|c|}{$\begin{array}{l}\text { Participação do tipo de trabalho na } \\
\text { composição da renda da classe (\%) }\end{array}$}} \\
\hline & \multirow[t]{2}{*}{ Mínima } & \multirow[t]{2}{*}{ Máxima } & & & & & & & & \\
\hline & & & & & LF & LNF & MF & MNF & $\mathrm{HF}$ & $\mathrm{HNF}$ \\
\hline $\mathrm{H} 1$ & - & 240 & 6,365 & 1,25 & 21,19 & 61,96 & 7,14 & 8,96 & 0,25 & 0,5 \\
\hline $\mathrm{H} 2$ & 241 & 480 & 23,4114 & 4,59 & 36,52 & 37,12 & 16,43 & 7,60 & 1,64 & 0,68 \\
\hline H3 & 481 & 720 & 31,8903 & 6,26 & 36,26 & 27,20 & 23,14 & 8,41 & 3,96 & 1,03 \\
\hline $\mathrm{H} 4$ & 721 & 1.200 & 63,4832 & 12,45 & 32,18 & 17,64 & 30,51 & 8,55 & 9,28 & 1,83 \\
\hline $\mathrm{H} 5$ & 1.201 & 1.440 & 22,1431 & 4,34 & 25,73 & 13,13 & 36,24 & 8,24 & 14,16 & 2,49 \\
\hline H6 & 1.441 & 1.920 & 41,3099 & 8,10 & 19,96 & 9,34 & 35,25 & 8,73 & 23,52 & 3,21 \\
\hline $\mathrm{H} 7$ & 1.921 & 2.400 & 35,9524 & 7,05 & 15,14 & 6,91 & 31,20 & 8,21 & 33,5 & 5,03 \\
\hline H8 & 2.401 & 3.600 & 63,5872 & 12,47 & 10,14 & 4,74 & 25,50 & 6,55 & 46,88 & 6,18 \\
\hline H9 & 3.601 & 4.800 & 41,7263 & 8,19 & 7,10 & 2,69 & 19,74 & 5,15 & 58,44 & 6,87 \\
\hline H10 & 4.801 & 7.200 & 53,7625 & 10,55 & 5,3 & 1,79 & 14,21 & 3,27 & 66,8 & 8,64 \\
\hline H11 & 7.201 & - & 126,0858 & 24,74 & 3,94 & 2,34 & 12,49 & 3,07 & 69,24 & 8,92 \\
\hline Total & & & 509,717 & 100,00 & 15,40 & 9,77 & 22,11 & 6,04 & 41,17 & 5,50 \\
\hline
\end{tabular}

Fonte: Elaboração própria.

Em R\$ de 2003 por mês.

nível desagregado, é possível identificar os efeitos setoriais levando em conta as diferenças estruturais e a alíquotas distintas para os vários impostos, que produzem diferenças setoriais no efeito das medidas tributárias sobre os custos e nos preços. Os níveis macro e setorial interagem porque o impacto no equilíbrio do mercado doméstico dos diferentes bens, decorrente das variações na produção, consumo, importações e exportações, é levado em consideração simultaneamente em ambos os contextos. As principais hipóteses para o "fechamento" do modelo são de mobilidade setorial dos fatores de produção, e uma política cambial de câmbio flutuante.

Os próximos parágrafos comentam os impactos macroeconômicos das medidas aqui consideradas, sintetizados na Tabela13. A variação do PIB real não é apresentada porque ela é praticamente nula, como discutido anteriormente.

Tabela 13: Síntese dos principais impactos macroeconômicos das medidas tributárias

\begin{tabular}{|c|c|c|c|c|c|}
\hline Agregado & Unidades & $\begin{array}{c}\text { Mudança da } \\
\text { base de incidência do } \\
\text { COFINS para VA }\end{array}$ & $\begin{array}{c}\text { Incidência do PIS/PASEP } \\
\text { e COFINS sobre } \\
\text { importações }\end{array}$ & $\begin{array}{l}\text { Extinção } \\
\text { da CPMF }\end{array}$ & Total \\
\hline $\begin{array}{l}\text { Impacto fiscal direto } \\
\text { Impacto fiscal total }\end{array}$ & $\begin{array}{c}\text { \% PIB a preços } \\
\text { de mercado }\end{array}$ & $\begin{array}{l}+1,6 \\
+0,2\end{array}$ & $\begin{array}{l}+1,0 \\
+0,6\end{array}$ & $\begin{array}{l}-2,5 \\
-1,3\end{array}$ & $\begin{array}{l}-0,1 \\
-0,5\end{array}$ \\
\hline $\begin{array}{l}\text { PIB a custo de fatores } \\
\text { Salário médio } \\
\text { Remuneração média do capital } \\
\text { Taxa de câmbio (R\$ / US\$) }\end{array}$ & $\begin{array}{c}\text { Variação \% } \\
\text { com relação ao } \\
\text { cenário básico }\end{array}$ & $\begin{array}{c}-0,4 \\
-0,6 \\
- \\
+0,2\end{array}$ & $\begin{array}{c}-1,2 \\
-2,1 \\
- \\
-1,2\end{array}$ & $\begin{array}{l}+1,9 \\
+2,7 \\
+1,8 \\
-1,0\end{array}$ & $\begin{array}{c}+0,3 \\
- \\
1,8 \\
-2,0\end{array}$ \\
\hline
\end{tabular}

Apesar do modelo oferecer uma fotografia completa da economia na hipótese de implantação de cada uma das medidas aqui consideradas, o interesse principal neste estudo é o aspecto tributário, mostrado nas duas primeiras linhas da Tabela 13. Elas indicam de modo eloquente a importância de utilizar um modelo de equilíbrio geral na avaliação de medidas deste tipo, como se discute a seguir.

A primeira linha mostra os impactos diretos, que seriam calculados em uma análise de equilíbrio parcial sob a hipótese ceteris paribus. Nas duas primeiras colunas, correspondentes a mudança da base de cálculo da COFINS e à incidência do PIS/PASEP e da COFINS sobre as importações, verifica-se que elas produziriam um aumento total de arrecadação $2,6 \%$ do PIB, enquanto a extinção da CPMF representaria uma perda de arrecadação de $2,5 \%$ do PIB. $O$ efeito direto líquido das três medidas sobre a arrecadação seria praticamente neutro, como indicado na última coluna. 
A segunda linha mostra o efeito avaliado sob a hipótese de equilíbrio geral, que leva em conta o ajuste necessário para restabelecer o equilíbrio econômico perturbado pelas medidas tributárias. Vê-se que o efeito sobre a arrecadação de cada uma das medidas considerando, com relação ao valor dela após a implantação das medidas indicadas nas colunas que a precedem. Eles são bem menores do que o impacto direto indicado na primeira linha: para a primeira medida os efeitos de equilíbrio geral quase anulam o ganho inicial de arrecadação, para a segunda medida eles reduzem o ganho à metade, e no caso da terceira medida eles compensam metade da perda de arrecadação. Conclui-se, portanto, que o erro cometido ao considerar apenas o impacto tributário imediato é da mesma ordem do impacto inicial. Ignorar os efeitos de equilíbrio geral pode comprometer irremediavelmente a avaliação do impacto fiscal como, por exemplo, no caso da primeira medida.

$O$ efeito destas medidas sobre o PIB a custo de fatores traduz o efeito sobre a renda nacional da mudança da tributação, e tem o sinal contrário àquele do efeito total sobre a arrecadação (segunda linha), como se poderia esperar. O seu valor absoluto é igual ao dobro, no caso das duas primeiras medidas, e igual a cerca de uma vez e meia, no caso da última medida, o valor absoluto do efeito fiscal total.

O sistema econômico responde às mudanças tributárias variando os preços relativos dos bens e dos fatores, que por sua vez induzem ajustes nas variáveis reais. São de especial interesse aqui os efeitos sobre três preços básicos da economia: salários, remuneração do capital, e câmbio, indicados nas três últimas linhas da Tabela 13, que seriam possivelmente tomados como nulos em uma análise que considerasse apenas o impacto direto.

O efeito sobre o bem estar dos consumidores pode ser medido pelo seu impacto no salário real, indicado na terceira linha. Para o conjunto das três medidas ele é nulo, pois o impacto positivo da extinção da CPMF $(2,7 \%)$ compensa o impacto negativo da mudança da base de tributação da COFINS $(-0,6 \%)$ e da incidência do PIS/PASEP e COFINS sobre as importações (-2,1\%). A decomposição do impacto no caso da extinção da CPMF entre os salários dos diferentes tipos de trabalhadores mostra que os trabalhadores mais beneficiados seriam os de baixa qualificação não-formais, cujo salário aumenta em 5,5\%. Apesar do aumento do salário dos diversos tipos de mão-de-obra ser diferente, a renda das famílias aumenta em cerca de $2 \%$, indistintamente ao longo das classes.

O impacto na remuneração do capital (juros), na quarta linha, é nulo no caso das duas primeiras medidas e, no caso da última, é igual a 1,8\%, correspondente a 20 pontos-base. ${ }^{38}$ Esta informação, tomada em conjunto com aquelas referentes ao PIB a custo de fatores, e aos salários, já comentadas, indica que o ganho de renda da extinção da CPMF é capturado pelo fator capital.

O conjunto das medidas leva a uma valorização da moeda nacional, indicada na última linha da Tabela 13, onde a taxa de câmbio (R\$ / US\$) se reduz em $2,0 \%$. A única medida que produz uma pequena desvalorização da moeda nacional é a mudança da base de cálculo da COFINS (+0,2\%).

Em conclusão, o uso de um modelo de equilíbrio geral nos permitiu analisar os principais efeitos agregados e setoriais das alterações recentes ocorridas no PIS/PASEP, na COFINS e na CPMF levando em conta as repercussões diretas e indiretas daquelas medidas.

\section{BIBLIOGRAFIA}

Adelman, I. \& Robinson, S. (1978). Income Distribution Policy in Developing Countries. Stanford University Press, Stanford, California.

Ahmed, V. (2007). Taxation reforms: A CGE- microsimulation analysis for Pakistan. PEP Research Network General Meeting, Lima, Peru.

Araújo, C. H. \& Ferreira, P. (1999). Reforma tributária, efeitos alocativos e impactos de bem-estar. Revista Brasileira de Economia, 53(2):133-66.

\footnotetext{
${ }^{38}$ Levando em conta que a taxa de remuneração do capital no cenário básico é de $11,4 \%$ ao ano.
} 
Auerbach, A. \& Kotlikoff, L. (1987). Dynamic Fiscal Policy. University Press, Cambridge.

Ballard, C., Fullerton, D., Shoven, J. B., \& Whalley, J. (1985). A General Equilibrium Model for Tax Policy Evaluation. University of Chicago Press, Chicago.

Baylor, M. \& Beauséjour, L. (2004). Taxation and economic efficiency: Results from a Canadian CGE model. Working Paper 2004-10, Department of Finance, Canada.

Berck, P., Golan, E., \& Smith, B. (1996). Dynamic revenue analysis for California. California Finance Department, State of California, EUA.

Cury, S. \& Coelho, A. (2006). From revenue to value added taxes: Welfare and fiscal efficiency effects in Brazil. Anais do Encontro Anual da ANPEC.

Derajavan, S., Lewis, J., \& Robinson, S. (1991). From stylized to applied models: Building multisector CGE models for policy analysis. Department of Agriculture and Resource Economics WP 616, University of California at Berkeley.

Dervis, K., De Melo, J., \& Robinson, S. (1982). General Equilibrium Models for Development Policy. Cambridge University Press, Cambridge.

Fehr, H. (2000). From destination-to origin-based consumption taxation: A dynamic CGE analysis. International Tax and Public Finance, 1(7).

Fochezatto, A. (2003). Reforma tributária, crescimento e distribuição de renda no Brasil: Lições de um modelo de equilíbrio geral computável. Economia Aplicada, 7(1).

Kume, H. (2004). Mudanças na COFINS e no PIS-PASEP e a estrutura de incentivos à produção doméstica. Mimeo, IPEA.

Lledo, V. (2001). Tax reform under fiscal adjustment: A CGE analysis of the Brazilian tax reform. Anais do XXIII Encontro Brasileiro de Econometria, Salvador, Bahia.

Lledo, V. (2005). Tax systems under fiscal adjustment: A dynamic CGE analysis of the Brazilian tax reform. IMF Working Paper 05/142.

Lofgren, H. R., Harris, L., \& Robinson, S. (2002). A standard computable general equilibrium model in GAMS. International Food Policy Research Institute Microcomputers in Policy Research Paper 5, Washington, D.C.

Maldonado, W., Tourinho, O., \& Valli, M. (2007). Endogenous foreign capital flow in a CGE model for Brazil: The role of the foreign reserves. Journal of Policy Modeling, 29:259-276.

Mercenier, J. \& Srinivasan, T. N. (1994). Applied General Equilibrium and Economic Development: Present Achievements and Future Trends. University of Michigan Press, Michigan.

Robinson, S., Yúnez-Naude, A., Hinojosa-Ojeda, R., Lewis, J., \& Devarajan, S. (1999). From stylized to applied models: Building multisector CGE models for policy analysis. North American Journal of Economics and Finance, 10:5-38.

Rosenthal, R. (2007). GAMS - A User's Guide. GAMS Development Corporation, Washington, D.C.

Shoven, J. B. \& Whalley, J. (1972). A general equilibrium calculation of the effects of differential taxation from income from capital in the US. Journal of Public Economics, 1:281-322. 
Shoven, J. B. \& Whalley, J. (1973). General equilibrium with taxes: A computation procedure and an existence proof. Review of Economic Studies, 60:475-490.

Shoven, J. B. \& Whalley, J. (1992). Applying General Equilibrium. Cambridge University Press, Cambridge.

Silva, N., Tourinho, O., \& Alves, Y. (2005). O impacto da reforma tributária na economia brasileira: Uma análise com um modelo CGE. In Secretaria do Tesouro Nacional, editor, Finanças Públicas: IX Premio Tesouro Nacional -2004, pages 359-424. IPEA, Brasília. Disponível também como Texto para Discussão do IPEA 1042, de setembro de 2004.

Silva, N., Tourinho, O., \& Alves, Y. (2006). Uma matriz de contabilidade social para o Brasil em 2003. Texto para Discussão do IPEA 1242.

Siqueira, R., Nogueira, J., \& Souza, E. (2001). A incidência final dos impostos indiretos no Brasil: Efeitos da tributação de insumos. Revista Brasileira de Economia, 55:513-544.

Tourinho, O., Kume, K., \& Pedroso, A. C. (2007). Elasticidades de Armington para o Brasil: 1986-2001. Revista Brasileira de Economia, 60.

Varsano, R., Pereira, T., Araújo, E., Silva, N., \& Ikeda, M. (2001). Substituindo o PIS e a COFINS - E por que não a CPMF? - Por uma contribuição não-cumulativa. Texto para Discussão do IPEA 832, IPEA, Rio de Janeiro.

Whalley, J. (1977). The United Kingdom tax system 1968-1970: Some fixed point indications of its economic impact. Econometrica, 45:1837-1858. 